\title{
Glacier calving observed with time-lapse imagery and tsunami waves at Glaciar Perito Moreno, Patagonia
}

\author{
MASAHIRO MINOWA, ${ }^{1}$ EVGENY A. PODOLSKIY, ${ }^{2,3}$ SHIN SUGIYAMA, ${ }^{1}$ \\ DAIKI SAKAKIBARA, ${ }^{2}$ PEDRO SKVARCA ${ }^{4}$ \\ ${ }^{1}$ Institute of Low Temperature Science, Hokkaido University, Nishi8, Kita19, Sapporo 060-0819, Japan \\ ${ }^{2}$ Arctic Research Center, Hokkaido University, Nishi11, Kita21, Sapporo 001-0021, Japan \\ ${ }^{3}$ Global Station for Arctic Research, Global Institution for Collaborative Research and Education, Hokkaido University, \\ Nishi11, Kita21, Sapporo 001-0021, Japan \\ ${ }^{4}$ Glaciarium - Glacier Interpretive Center, 9405 El Calafate, Santa Cruz, Argentina \\ Correspondence: Masahiro Minowa <minowa.masahiro@gmail.com>
}

\begin{abstract}
Calving plays a key role in the recent rapid retreat of glaciers around the world. However, many processes related to calving are poorly understood since direct observations are scarce and challenging to obtain. When calving occurs at a glacier front, surface-water waves arise over the ocean or a lake in front of glaciers. To study calving processes from these surface waves, we performed field observations at Glaciar Perito Moreno, Patagonia. We synchronized time-lapse photography and surface waves record to confirm that glacier calving produces distinct waves compared with local noise. A total of 1074 calving events were observed over the course of $39 \mathrm{~d}$. During austral summer, calving occurred twice more frequently than in spring. The cumulative distribution of calving-interevent time interval followed exponential model, implying random occurrence of events in time. We further investigated wave properties and found that source-to-sensor distance can be estimated from wave dispersion within $\sim \mathbf{2 0} \%$ error. We also found that waves produced by different calving types showed similar spectra in the same frequency range between $0.05-0.2 \mathrm{~Hz}$, and that the amplitude of surface waves increased with the size of calving. This study demonstrates the potential of surface-wave monitoring for understanding calving processes.
\end{abstract}

KEYWORDS: calving, glacier monitoring, glaciological instruments and methods

\section{INTRODUCTION}

Rapid mass loss from calving glaciers is influencing the largescale mass loss of ice sheets, icefields and glaciers (Gardner and others, 2013). Calving, or iceberg detachment from glacier termini, is known to be the most significant processes for mass loss from calving glaciers in Patagonia (Rignot and others, 2003; Schaefer and others, 2015), Alaska (Arendt and others, 2002; Larsen and others, 2015; Truffer and Motyka, 2016), half the mass loss from the Greenland ice sheet (van den Broeke and others, 2009; Enderlin and others, 2014) and nearly $45 \%$ of the mass loss from the Antarctic ice sheet (Rignot and others, 2013). Particularly in the Patagonia icefields, which form the largest temperate glacier system in the Southern Hemisphere, ice mass is being lost at one of the fastest rates in the world (Jacob and others, 2012; Gardner and others, 2013). Of 69 major outlet glaciers in the region, more than $90 \%$ of ice fronts end in lakes and the ocean (Warren and Aniya, 1999). The front positions of these calving glaciers have been retreating over the last few decades (Aniya and others, 1997; Rignot and others, 2003; Lopez and others, 2010) as a result of increasing ice discharge through calving (Sakakibara and Sugiyama, 2014; Schaefer and others, 2015), causing the rapid mass loss of the ice fields (Willis and others, 2012).

Seismic signals have been used to monitor calving activity in Greenland (Amundson and others, 2008, 2010; Tsai and others, 2008; Nettles and Ekström, 2010; Walter and others, 2013), Alaska ( $\mathrm{O}^{\prime} \mathrm{Neel}$ and others, 2007; Bartholomaus and others, 2012, 2015), Antarctica
(MacAyeal and others, 2009; Chen and others, 2011) and Svalbard (Köhler and others, 2012, 2015, 2016). These studies revealed that calving, which does not involve capsizing, generates a distinctive frequency of seismic signals between 1 and $3 \mathrm{~Hz}\left(\mathrm{O}^{\prime} \mathrm{Neel}\right.$ and others, 2007; Podolskiy and Walter, 2016). Moreover, Bartholomaus and others (2015) revealed that seismic signals were useful, not only to detect glacier calving, but also to locate calving events, characterize the calving style and estimate calving flux. Similar to these seismic signal studies, additional work endeavored to use acoustic signals to study calving (Pettit, 2012; Pettit and others, 2012, 2015; Deane and others, 2014; Glowacki and others, 2015). These studies revealed that high-frequency acoustic signals (up to several tens of kilohertz) could be used to detect individual calving events (Glowacki and others, 2015).

When icebergs break off into the water, surface-water waves arise over the ocean or a lake in front of calving glaciers. Several studies have been used to study surface waves to understand calving processes by in situ observations (Haresign, 2004; lizuka and others, 2004; Marchenko and others, 2012; Lüthi and Vieli, 2016; Vaňková and Holland, 2016) and numerical modeling (Massel and Przyborska, 2013). For example, lizuka and others (2004) observed surface waves in front of Glaciar Perito Moreno (GPM), a lake-terminating glacier in the Southern Patagonia Icefield (SPI). They collected $12 \mathrm{~d}$ of surface-wave observations with sampling rates of 5 or $15 \mathrm{~s}$ measuring 68 events generated by calving. The maximum amplitude was 0.48 
$\mathrm{m}$, and water-level oscillations lasted for $\sim 50 \mathrm{~min}$. According to seismic and acoustic signal studies, signal frequency contains important information about calving size and style (e.g., Bartholomaus and others, 2015; Glowacki and others, 2015). However, with low sampling rates of 5-15 s, information can be undersampled and lost. Vaňková and Holland (2016) performed year-round surface-wave observation at five sites by using bottom pressure meters attached to a mooring in Sermilik Fjord, East Greenland. However, because the closest sensor was located $30 \mathrm{~km}$ away from Helheim Glacier, they observed only 16 events generated by calving. Surface waves attenuate with distance, and high-frequency waves decay faster than low-frequency waves (Lamb, 1932). Therefore, it is important to observe surface waves in the vicinity of a glacier front. By using numerical modeling, Massel and Przyborska (2013) studied idealized wave propagation from an object falling into water for four different scenarios and obtained different wave patterns for various source mechanisms. These studies implied that observations of surface waves are useful not only for monitoring calving activity, but also for characterizing calving style or size. However, to our knowledge, there is no such detailed study with relatively long-term surface-wave observations near a glacier front.

In terms of calving mechanisms, calving can be classified into four different styles (Benn and others, 2007). The first style is subaerial calving of a piece of ice falling from an ice cliff. This style involves the propagation of a fracture due to ice flow velocity gradient (e.g., Meier and Post, 1987) and/or undercutting by high subaqueous melting (e. g., Motyka and others, 2003; Bartholomaus and others, 2012). Secondly, when a glacier flows into a deep fjord, the ice front is close to flotation. The ice velocity gradient and high buoyancy may enhance crevasses from the glacier bottom to the surface and generate full-ice-thickness tabular icebergs in grounded glaciers that frequently capsize after detaching (Howat and others, 2007; Amundson and others, 2010; Bassis and Jacobs, 2013; James and others, 2014). In addition to this, tabular icebergs sporadically detach from the freely floating ice tongues and ice shelves when a glacier flows into cold water (Lazzara and others, 1999; Warren and others, 2001; Boyce and others, 2007; Bassis and others, 2008; Trüssel and others, 2013; Truffer and Motyka, 2016). Thirdly, similar to subaqueous melting, thermal notch formation at the waterline has also been suspected as a driving mechanism of subaerial calving (e.g., Kirkbride and Warren, 1997; Röhl, 2006; Minowa and others, 2017). Finally, for the fourth calving style, ice detaches not only from the subaerial part of a calving front, and sometimes icebergs float up from underwater (e.g., Hunter and Powell, 1998; Truffer and Motyka, 2016). These icebergs usually contain debris. However, in general, neither a question about how common each calving style is, nor a question which calving styles can be associated with surface waves are well addressed.

In this study, we measured surface waves generated by calving events at GPM, a lake-terminating glacier, in the SPI at 300-1800 $\mathrm{m}$ distance from the calving front. First, we confirmed with time-lapse photography analysis that glacier calving generates surface waves that are distinctive from other local sources such as wind or tourist boats. Next, we developed a detector to count the occurrence rate based on a prescribed threshold for wave height, as well as a distance estimator based on dispersion analysis.
Corresponding calving styles were classified by using timelapse images. These surface waves and corresponding calving styles enable us to explore the properties of surface waves generated by glacier calving for conditions of a lake-terminating glacier.

\section{STUDY SITE}

GPM $\left(50.5^{\circ} \mathrm{S}, 73.2^{\circ} \mathrm{W}\right)$ stretches over a length of $30 \mathrm{~km}$ from Cerro Pietrobelli (2950 m a.s.l.) to Lago Argentino (177.5 m a.s.l.). The glacier covers an area of $259 \mathrm{~km}^{2}$ (De Angelis, 2014), and calves into two lakes, Brazo Rico and Canal de los Témpanos, which are a part of Lago Argentino (Fig. 1). The lower part of the glacier is heavily crevassed due to a divergence of the flow field, and icebergs frequently break off from the calving front (Fig. 1b). The height of the ice cliff above the lake surface is between 55 and $75 \mathrm{~m}$ (Naruse and others, 1992). Water depth near the calving front in Brazo Rico is shallower than $70 \mathrm{~m}$, and deepens to $\sim 120 \mathrm{~m}$ about $500 \mathrm{~m}$ from the ice front (Fig. 1b) (Sugiyama and others, 2016). According to previous observations on the glacier surface elevation and bathymetry at GPM, the glacier is well above the flotation level (Naruse and others, 1992; Sugiyama and others, 2016). Therefore, we would expect the ice front to be grounded.

In Brazo Rico, there are two possibilities for non-calving events to disturb surface-wave observation. Since GPM is listed as a World Heritage Site in Argentina, a large number of tourist boats visit the glacier frequently during the day. Boats cruise along the glacier front and some of the tourists come ashore to walk to the glacier from the harbor (Fig. 1b). Also, as it is aptly referred to as the Land of Tempest (Shipton, 1963), Patagonia is characterized by consistently strong westerly winds and the wind speed is enhanced particularly in summer (Stuefer, 1999; Lenaerts and others, 2014), leading to the generation of surface waves.

\section{METHODS AND DATA}

\subsection{Time-lapse photography}

To observe glacier calving, we took photographs of the calving front every $1 \mathrm{~min}$ with time-lapse cameras (Garden WatchCam, Brinno Co., Taipei $1280 \times 1024$ pixels, with $5.01 \mathrm{~mm}$ focal length, and corresponding ice cliff height from $\sim 100$ to 150 pixels). The photographs were utilized to distinguish calving-generated surface waves from those due to other sources. Cameras were installed at four different positions during the field observations (Fig. 1): camera 1 was operated from December 2013 to January 2014 and in October 2014, camera 2 from December 2013 to January 2014, camera 3 from February to March 2016 and camera 4 in October 2014. No images were recorded at nighttime. Typically, daylight hours were 19\% longer in December (16 h) compared with October (13 h) during the observations.

We categorized the calving events that were observed into four groups (Fig. 2): Topple - an ice tower toppling into the lake; Drop - an ice block dropping into the water; Serac serac slipping down to the lake; and Subaqueous - iceberg floating up to the lake surface. These were the most common calving styles in GPM, and 420 calving events in total were classified over the three periods (Table 1). Although the shooting interval was relatively low, sequences of the time-lapse camera images provided sufficient 

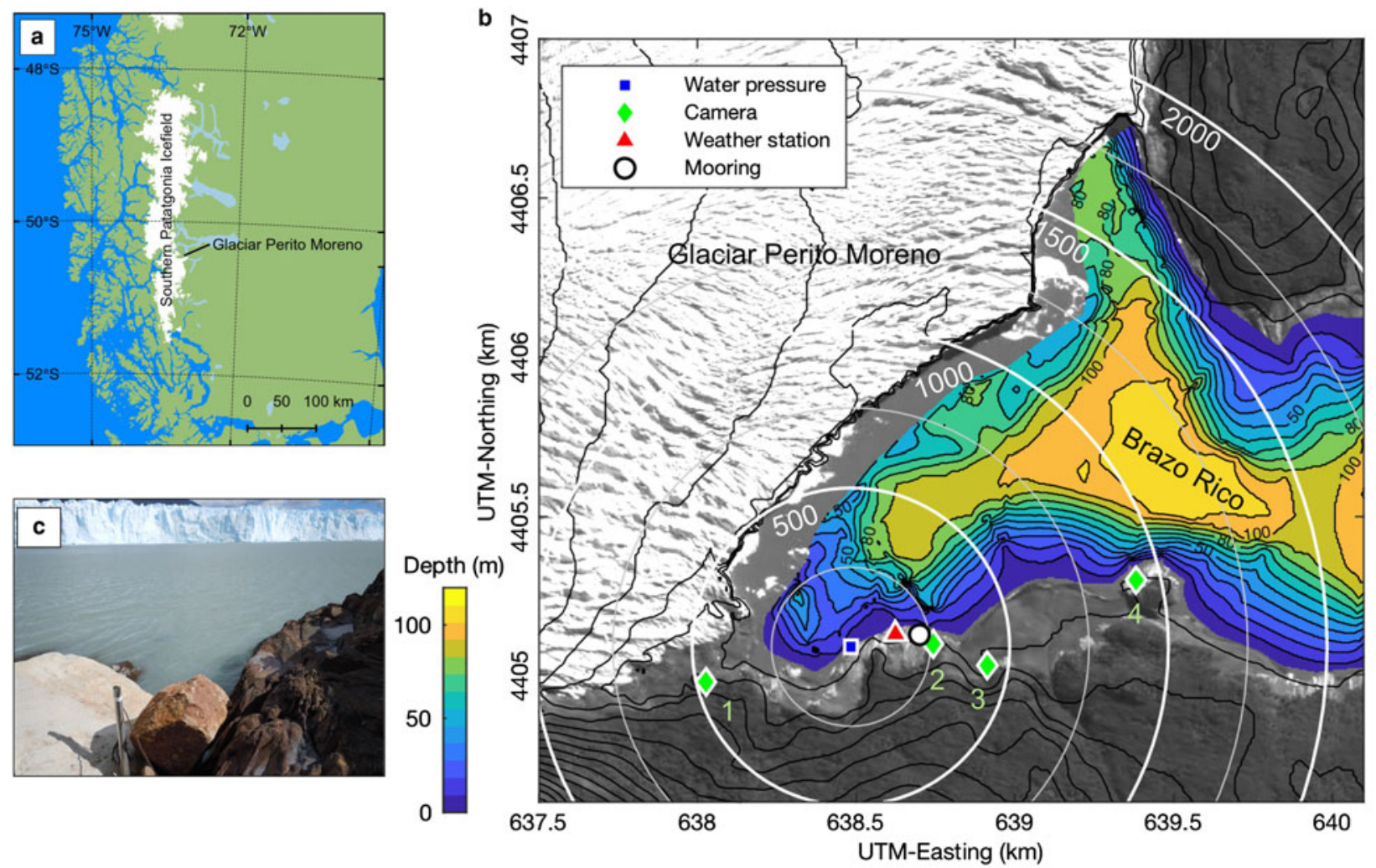

Fig. 1. (a) A map showing the study site. (b) Satellite image of Glaciar Perito Moreno with instrument locations. The background image was taken by ALOS/PRISM on 29 March 2008. Lake bathymetry in front of Glaciar Perito Moreno with contour intervals of $10 \mathrm{~m}$. Circles indicate distances every $250 \mathrm{~m}$ from the water pressure sensor (blue square). (c) Photograph of the pressure measurement site.

information to distinguish the styles. We distinguished Topple from Drop by observing crevasse widening. Topple was observed after crevasse opening for several minutes, while Drop occurred without any precursors (Fig. 2). Subaqueous calving was distinguished from other subaerial calving by noting a lack of frontal changes and sediment inclusion in icebergs. When subaqueous caving occurred, a relatively large single iceberg appears without any geometrical change above the water surface. We sometimes observed debris-rich icebergs, which indicated their basal origin. Location of each calving event was mapped onto a Landsat-8 Operational Land Imager (OLI) band 8 image (15 $\mathrm{m}$ resolution) based on distinctive ice features (ice front geometry, large crevasses, ice tower), which were recognizable on the time-lapse and satellite images (Fig. 3). The Landsat images were taken on 10 December 2013, 3 October 2014 and 22 March 2016.

\subsection{Measurement of surface waves}

We observed lake surface waves by operating a water pressure sensor (HOBO U20, Onset Co.) in the lake. The sensor was installed at the coast of Brazo Rico $\sim 50 \mathrm{~cm}$ below the water surface by fixing the sensor on a $2 \mathrm{~m}$ aluminum pipe, fixing the pipe securely with boulders as shown in Figure 1c. The water depth below the sensor was $\sim 10 \mathrm{~m}$, meaning that the measurements were done not in the surf zone, which could complicate the analysis (e.g., Horikawa and Kuo, 1966). The distance from the sensor to the ice front ranged from 300 to $1800 \mathrm{~m}$ (Fig. 1b). We operated the water pressure sensor in three periods: period 1: 15 December 2013-4 January 2014 (19.6 d), period 2: 6-20 October 2014 (13.6 d) and period 3: 27 February-4 March 2016 (5.4 d). The accuracy of the sensor was equivalent to a water level of $\pm 5 \mathrm{~mm}$ with a resolution of $1.4 \mathrm{~mm}$. Water pressure was recorded every $2 \mathrm{~s}(0.5 \mathrm{~Hz})$. The corresponding highest observable Nyquist frequency, i.e., half of the sampling rate, was $0.25 \mathrm{~Hz}$. The water pressure $P_{\mathrm{w}}$ was converted to water level $H_{\mathrm{w}}$ by correcting for atmospheric pressure variations using the following equation:

$$
H_{\mathrm{w}}=\left(P_{\mathrm{w}}-P_{\mathrm{a}}\right) / \rho_{\mathrm{w}} g
$$

where $\rho_{\mathrm{w}}, g$ and $P_{\mathrm{a}}$ are the density of fresh water $\left(1000 \mathrm{~kg} \mathrm{~m}^{-3}\right)$,

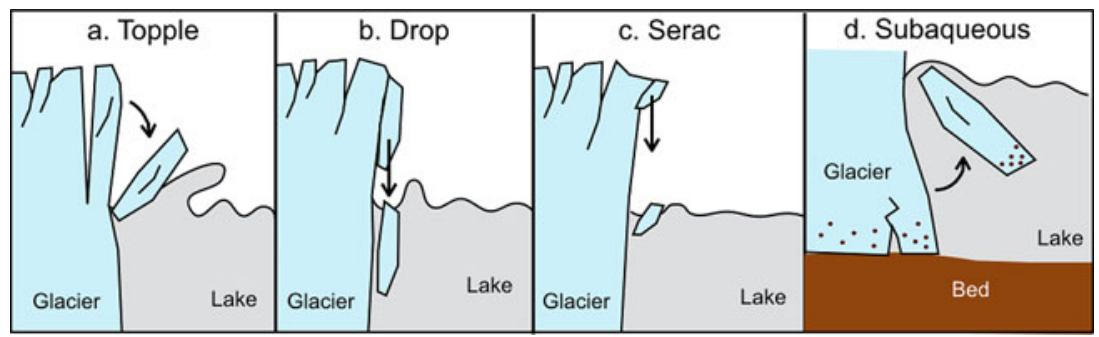

Fig. 2. Illustration of the most common calving styles at GPM. 
Table 1. Occurrence and fraction (\% in the parentheses) of four different calving styles for periods 1,2 and 3

\begin{tabular}{lclll}
\hline & $\begin{array}{l}\text { Period 1 } \\
\text { 15 December } \\
\text { 2013-4 }\end{array}$ & $\begin{array}{l}\text { Period 2 } \\
6-20\end{array}$ & $\begin{array}{l}\text { Period 3 } \\
\text { October }\end{array}$ & $\begin{array}{l}\text { Total } \\
\text { February-3 }\end{array}$ \\
& January 2015 & 2014 & March 2016 & \\
& $39(14 \%)$ & $9(13 \%)$ & $9(16 \%)$ & $57(14 \%)$ \\
Topple & $135(46 \%)$ & $32(45 \%)$ & $30(53 \%)$ & $197(47 \%)$ \\
Drop & $111(38 \%)$ & $30(42 \%)$ & $15(26 \%)$ & $156(37 \%)$ \\
Serac & $7(2 \%)$ & $0(0 \%)$ & $3(5 \%)$ & $10(2 \%)$ \\
Subaqueous & 292 & 71 & 57 & 420 \\
Total & & & & \\
& & & &
\end{tabular}

gravitational acceleration $\left(9.81 \mathrm{~m} \mathrm{~s}^{-2}\right)$ and air pressure measured with a local automatic weather station (AWS) (Fig. 1b), respectively. After correcting for atmospheric pressure variations, we also applied a high-pass filter with a cutoff period of $1 \mathrm{~h}$ to obtain a detrended water-wave signal. Such high-pass filter was used in order to remove any seasonal variations in the lake level.

Gravitational water waves considered in this study were assumed to propagate in ice-free water (according to Landsat 8 satellite imagery and time-lapse photographs; Fig. 3). Surface gravity waves propagate according to the dispersion relationship between a wavenumber $k$ and an angular frequency $\omega$ (Munk and others, 1963):

$$
\omega^{2}=g k \tanh (k h)
$$

where $k$ is the wavenumber $\left(\mathrm{m}^{-1} ; k=2 \pi / \lambda\right.$, where $\lambda$ is a wavelength) and $h$ is the water depth. In particular, in a case of $\lambda<h$, the surface wave is considered to be a deepwater wave. For deep-water waves, $k$ is large enough to fulfill $k h \gg 1$, and thus tanh $(k h) \approx 1$. Therefore, the dispersion relation (Eqn 2) can be approximated as

$$
\omega^{2}=g k
$$

This equation leads to a phase velocity $C=\omega / k=g / \omega$ and a group velocity $U=\partial \omega / \partial k=g /(2 \omega)=C / 2$ (Munk and others, 1963; Bromirski and Duennebier, 2002). The relationship $U \propto 1 / \omega$ implies that the arrival time of the surface wave generated by calving is linearly dependent on the wave frequency (MacAyeal and others, 2009).

To investigate wave properties, we performed spectral analysis of observed surface waves. First, we calculated a spectrogram of the surface wave by using a Matlab function 'spectrogram()' with a moving window of $20 \mathrm{~s}$ and an overlap of $90 \%$ (these parameters were chosen empirically as optimal for temporal and frequency resolution). Second, we calculated power spectral density using the Matlab ' $\mathrm{ftt}()^{\prime}$ function with $512\left(2^{8}\right)$ sampling points.
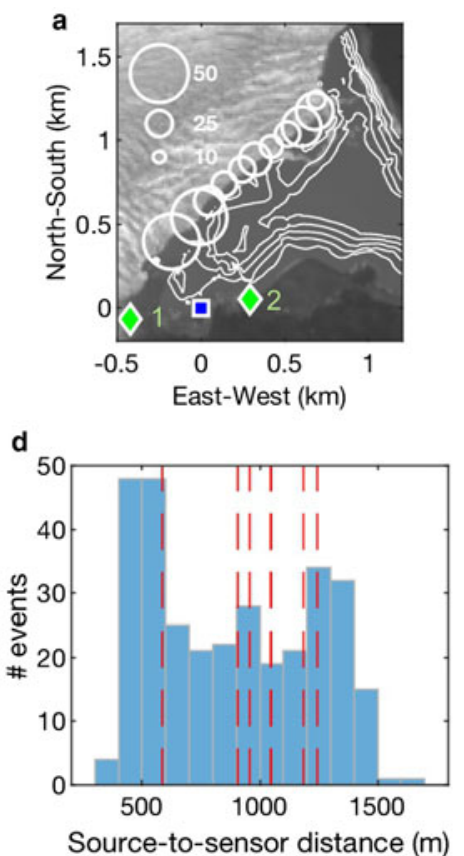
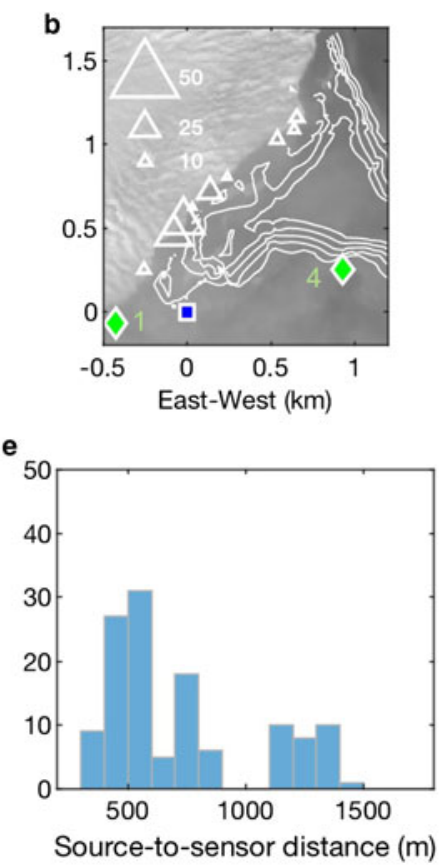
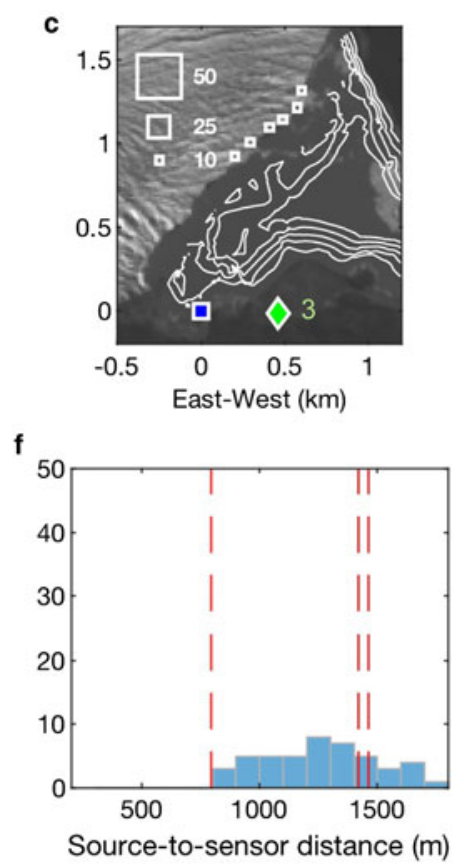

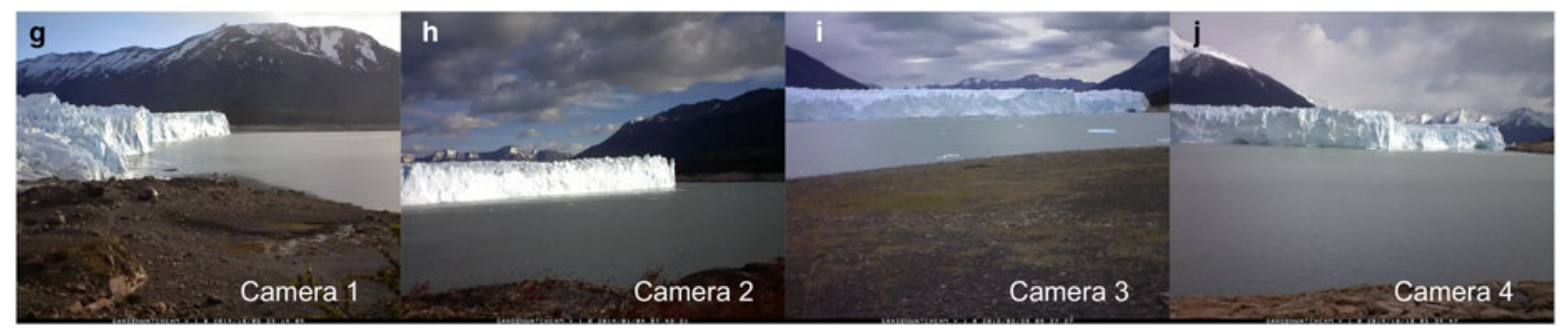

Fig. 3. Satellite images showing the location of calving events obtained by comparing time-lapse and satellite images in (a) period 1, (b) period 2 and (c) period 3 (marker size is proportional to the number of events). Blue squares and green diamonds indicate the location of the water pressure sensor and time-lapse cameras, respectively. Contours indicate water depth with intervals of $20 \mathrm{~m}$. (d)-(f) Histograms of source-tosensor distance determined from (a)-(c). Vertical dashed red lines indicate the locations of subaqueous calving. (g)-(j) Examples of the timelapse camera images. 
Surface-water waves associated with glacier calving were identified by defining a wave height threshold. We detect each calving event by identifying a signal with an amplitude $>0.13 \mathrm{~m}$. The $0.13 \mathrm{~m}$ threshold was determined by comparing surface waves and time-lapse images. The smallest calving event recorded by the time-lapse cameras, which was also recorded by the pressure sensor, had a $0.13 \mathrm{~m}$ maximum wave amplitude. However, at GPM, as we noted before, the source of surface waves was not always a result to glacier calving. During daytime hours, tourist boats approached the glacier many times. During the period indicated by the gray lines in Figure 5, the boats appeared in the photographs. The boats do generate waves, but they were smaller than the calving signals. Another possible local noise is the strong Patagonian wind. However, the wave height was $<0.1 \mathrm{~m}$ even during the periods with winds higher than $14 \mathrm{~m} \mathrm{~s}^{-1}$. Therefore, neither the boat traffic nor wind was misinterpreted as calving in our analysis.

In order to investigate the performance of the detection method, numbers of events were obtained from surface waves and time-lapse imagery. With the $0.13 \mathrm{~m}$ threshold, we detected 1074 events in total, including 239 events detected at night. The number of daytime false-positive and false-negative detections were 42 and 45 events, respectively. Thus, the uncertainly of the method was $10 \%$. The most of the false-positive detections arose from large calving events, which produced long-lasting surface waves with relatively high amplitude. On the other hand, falsenegative detections were associated with small calving events, which produced small surface waves. These events were hard to detect due to their low signal-to-noise ratio.

Since the lake level occasionally dropped below the sensor level during our field activity in period 1, it is necessary to evaluate a negative wave amplitude clipping. This clipping is a possible cause of spectrum blurring and changes of their characteristics. To evaluate the influence of this effect, we artificially clipped well-recorded waves $0.1 \mathrm{~m}$ from their lowest negative amplitude and analyzed their spectra to see what difference was produced, if any. The power of a wave was decreased $16 \%$ from the original, whereas the general trend of the spectrum did not change except for the low frequency of the waves. At the lowest frequency of the clipped waves $(<0.002 \mathrm{~Hz})$, the power of the wave increased substantially when compared with the original wave. Therefore, negative amplitude clipping likely causes higher power at the low frequency, but only during period 1 .

\section{RESULTS}

\subsection{Time-lapse photography}

A total of 420 events were identified by visual inspection on time-lapse camera images and manually localized on corresponding satellite imagery (Fig. 3). These calving events are non-uniformly distributed along the calving front. In period 1 , a large number of events clustered at 700 and 1100$1300 \mathrm{~m}$ from the pressure sensor (Fig. 3d). This spatial distribution was similar in period 2 (Fig. 3e).

Among the 420 calving events, 57 events (14\%) were categorized as Topple, 197 events (47\%) were Drop and 156 events $(37 \%)$ were Serac. Only ten events $(2 \%)$ were Subaqueous (Table 1). This distribution of calving styles was similar between the three periods. Drop and Serac accounted for $80-90 \%$ of the calving events in the periods, and Topple accounted for $\sim 15 \%$. Subaqueous calving was observed in periods $1(2 \%)$ and $3(5 \%)$ but was never observed in period 2 (Table 1).

Figure 4 shows the number of calving events per day classified by their styles. Serac and Drop were more common than the other two styles and recorded every day during the three observation periods. Topple was also observed frequently, but not every day. We recorded only seven and three subaqueous-calving events in periods 1 and 3, respectively. In period 1, subaqueous-calving events occurred every day from 27 to 31 December 2013 and events were more frequent than in the other periods (Fig. 4a). Temporal variations in the daily event number was greater than those in the other two periods (Figs 4b, c).

\subsection{Surface waves generated by calving}

Figure 5a shows an example of surface waves recorded for eight hours from 9:00 to 17:00 on 17 December 2013 in
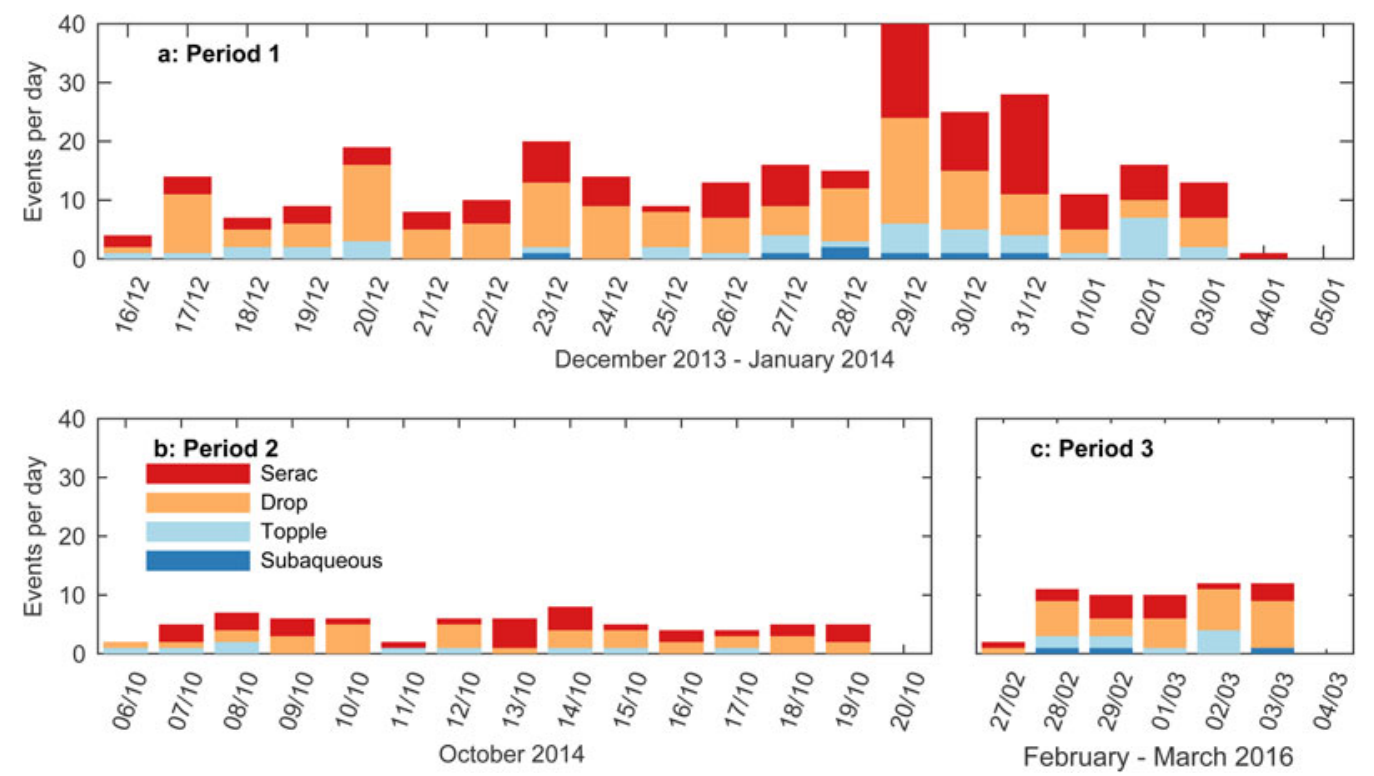

Fig. 4. Daily number of calving events classified by their style in (a) period 1, (b) period 2 and (c) period 3. 

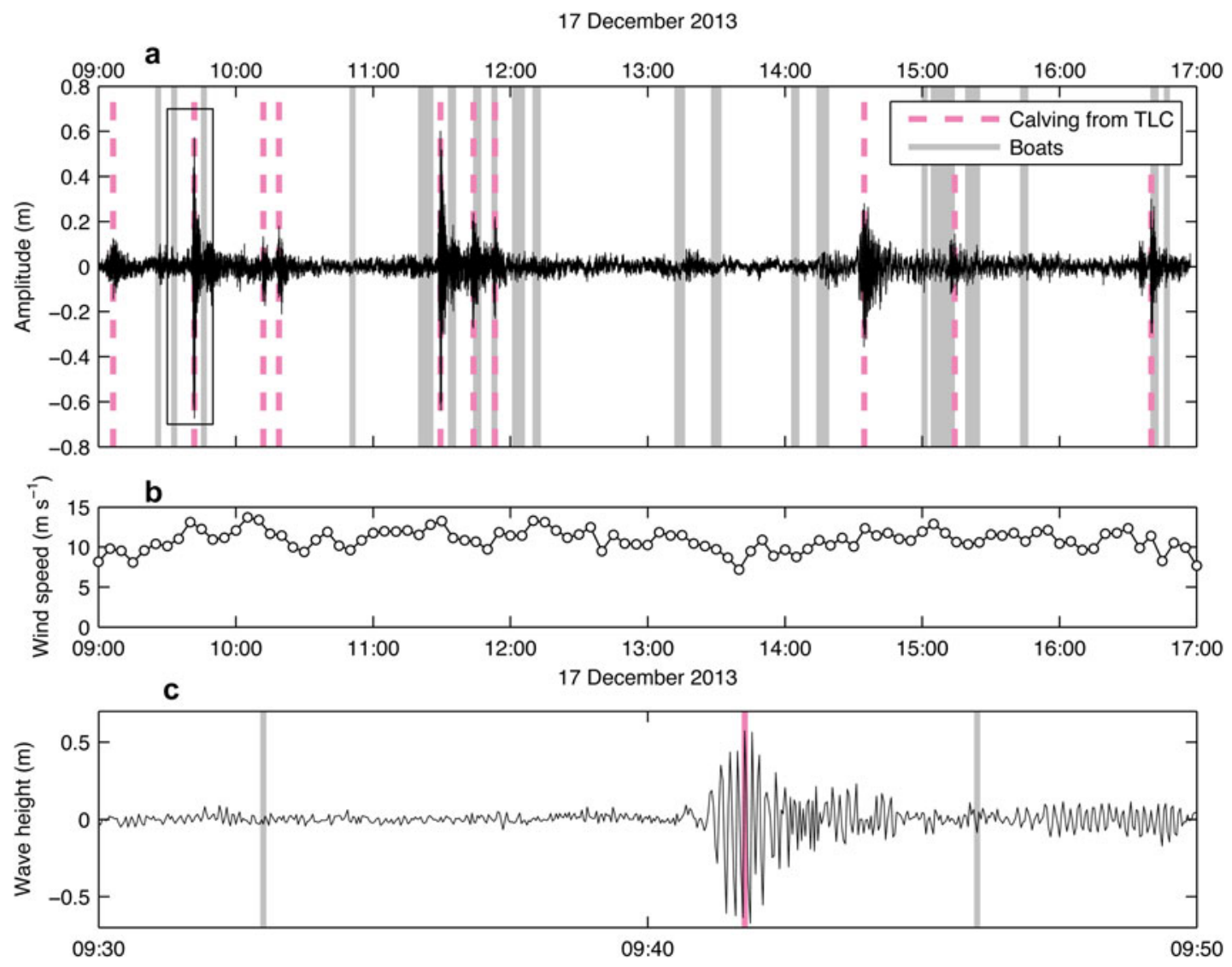

Fig. 5. (a) An example of observed surface-wave records for $8 \mathrm{~h}$ spanning from 9:00 to 17:00 on 17 December 2013 when the strongest westerly wind was recorded during the field campaign. Red thick dashed lines and grey lines highlight calving events observed by the time-lapse cameras and appearance of a tourist boat in the photographs, respectively. The box indicates the region enlarged in (c). (b) Wind speed recorded during the same period. (c) Enlarged surface wave between 9:30 and 9:50.

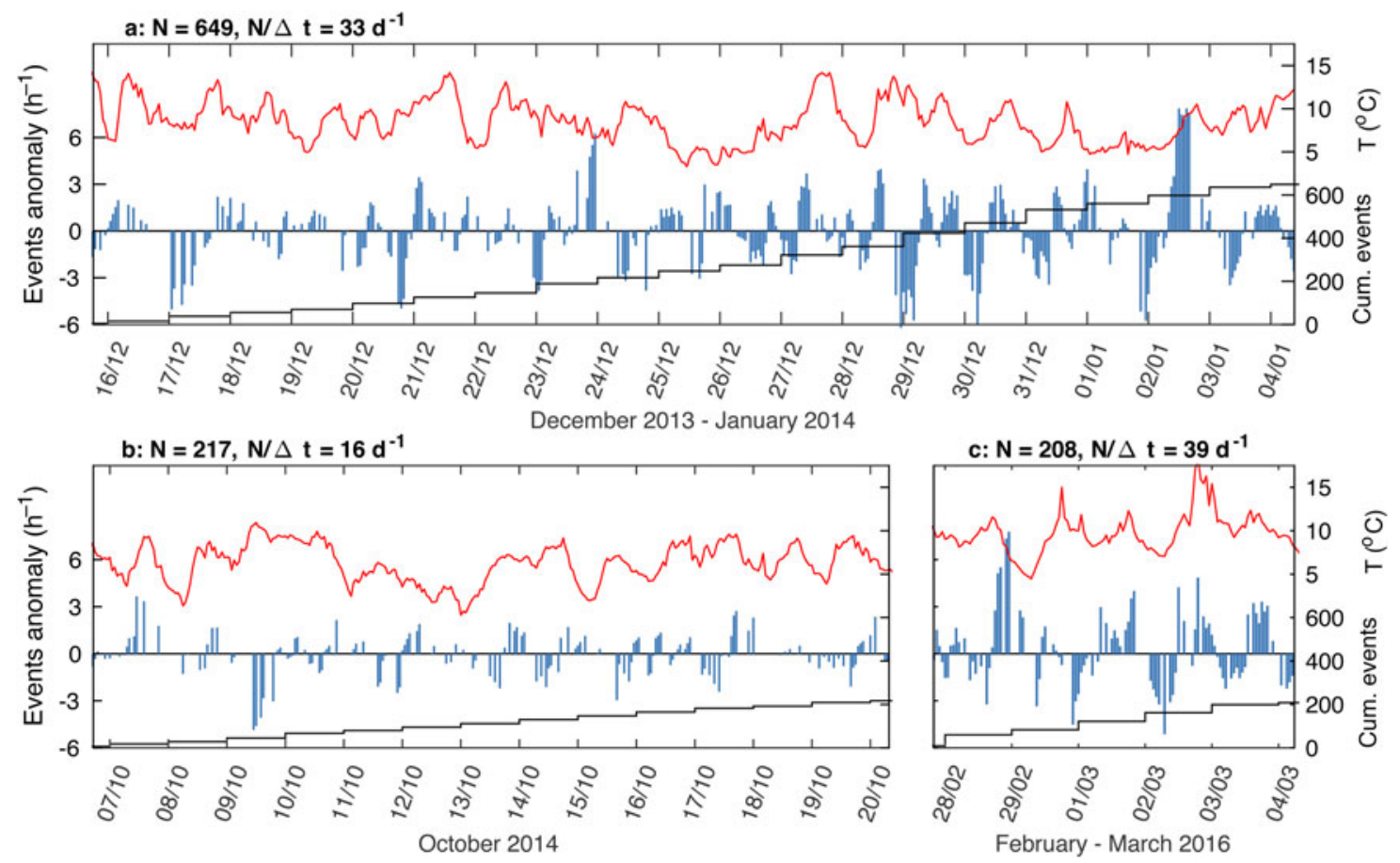

Fig. 6. Calving events detected by surface wave in (a) period 1, (b) period 2 and (c) period 3. Blue bars indicate anomaly in the event frequency relative to a $50 \mathrm{~h}$ moving average. Black line indicates the daily cumulative number of events. The total number of detected events and the mean calving rate are shown in each panel. Red line indicates hourly mean air temperature observed by the AWS at the glacier front. 
local time, during the most windy period in our observation period (Fig. 5b). When calving occurred, it generated impulse waves (Figs 5a, c). For example, we observed ten surface waves generated by calving on December 17, which were confirmed by time-lapse images (Fig. 5a). Maximum amplitude ranged from 0.13 and $0.6 \mathrm{~m}$, with wave durations of $\sim 10-30$ min (Figs 5a, c). This wave height and duration are similar to those previously observed in Brazo Rico by lizuka and others (2004). In addition to these waves caused by calving events, smaller waves were recorded and they were not associated with calving captured by the images (Fig. 5a). We assume these waves were generated by small calving, wind, boats or some other sources of noise outside the field of view.

By applying the criteria of calving-generated waves described in the Methods section, we obtained 649 $\left(33 \mathrm{~d}^{-1}\right), 217\left(16 \mathrm{~d}^{-1}\right)$ and 208 events $\left(39 \mathrm{~d}^{-1}\right)$ during periods 1, 2 and 3, respectively (Fig. 6). In periods 1 and 3, calving occurred 2.1 and 2.4 times more frequently than in period 2. These events were non-uniformly distributed over time. For example, in period 1, the number of events increased to $6 \mathrm{~h}^{-1}$ from 27 December to 1 January and decreased towards the end of the measurements (Fig. 6a). The number of events in period 3 varied in time as well, whereas events were more uniformly distributed over time in period 2 (Fig. 6b). Despite the difference in the calving frequency, the mean maximum amplitudes were similar for all periods: $0.36 \pm 0.24 \mathrm{~m}( \pm \mathrm{SD}), 0.33 \pm 0.22 \mathrm{~m}$ and $0.34 \pm$ $0.22 \mathrm{~m}$ for the periods 1,2 and 3, respectively. Figures 6 and 7 show anomaly in hourly calving rates and hourly variations in the number of events averaged over each period, respectively. Figures $6 \mathrm{a}$, c suggest decrease in calving rates at night. However, there was no clear diurnal variation in the number of detected events in all the periods.

Figure 8 presents cumulative distribution functions of waiting time $\tau(\mathrm{min})$ in comparison to best-fit power-law and exponential models. The waiting time $\tau$ spanned more than one order of magnitude. The minimum $\tau$ was $5.8,3.1$ and $3.9 \mathrm{~min}$ in periods 1,2 and 3, respectively. The maximum $\tau$ was 516.4, 640.5 and $323 \mathrm{~min}$ in periods 1,2 and 3 with a mean $\tau$ of $43.6,90.7$ and 37.7 min, respectively. In general, the exponential distribution reproduced better the observed data than the power-law model (Fig. 8).

\subsection{Surface waves generated by subaerial and subaqueous calving}

Figure 9 shows an example of surface waves generated by a subaerial-calving event (Drop), which was an ice tower break-off into the lake at the location $1310 \mathrm{~m}$ from the sensor (Figs $9 \mathrm{a}-\mathrm{c}$ ). The generated wave had a positive onset; its amplitude decreased gradually over five minutes after the maximum wave amplitude of $0.4 \mathrm{~m}$ (Fig. 9d). Lowfrequency surface waves $(\sim 0.05 \mathrm{~Hz})$ arrived first at the sensor, followed by higher frequency waves up to $0.2 \mathrm{~Hz}$ (Fig. 9e). This corresponds to the frequency dispersion of multiple-frequency waves as was previously reported by MacAyeal and others (2006, 2009) for micro-tsunamis observed in Antarctica. The wave had a peak amplitude at a frequency of $0.06 \mathrm{~Hz}$, with relatively strong power between 0.02 and $0.15 \mathrm{~Hz}$ (Fig. 9f).

Figure 10 shows an example of a surface wave generated by a subaqueous-calving event that occurred at $960 \mathrm{~m}$ from the sensor. In contrast to the subaerial-calving event, surface waves generated by subaqueous-calving events had different characteristics in terms of amplitude and frequency (Fig. 10). The wave had no clear onset and its amplitude suddenly dropped by $0.3 \mathrm{~m}$ after the maximum amplitude of $0.4 \mathrm{~m}$ (Fig. 10d). Low-frequency wave arrived first $(0.05 \mathrm{~Hz})$ at the sensor. The dominant frequency was $0.11 \mathrm{~Hz}$, and the power was concentrated between 0.1 and $0.13 \mathrm{~Hz}$ (Fig. 10f). The signal power was smaller than that of waves generated by subaerial calving. The waves did not have high-frequency content $(0.13-0.25 \mathrm{~Hz})$ compared with subaerial events (Figs 9e, 10e).

\section{DISCUSSION}

\subsection{Glacier calving at Glaciar Perito Moreno}

The location of calving events was unevenly distributed in periods 1 and 2 (Fig. 3). Calving events clustered in $\sim 700$ and 1100-1300 $\mathrm{m}$ from the pressure sensor. The distribution seems to be controlled by the lake bathymetry in Brazo Rico near the ice front (Fig. 1). The lake bathymetry forms a relatively rugged basin (Fig. 1). The lake is $20-40 \mathrm{~m}$ shallower at $\sim 700$ and $1100-1300 \mathrm{~m}$ from the sensor, and the ice cliff is higher at this region by $\sim 20 \mathrm{~m}$ (Fig. 1). Higher ice cliffs will lead to larger tensile stresses affecting calving activity (Hanson and Hooke, 2003). In addition to this, gaps between crevasses are larger (Fig. 1), suggesting that the horizontal strain rate is greater in these regions. Most likely, these geometrical and dynamic conditions affect the observed location of the calving events (Fig. 3).

Only ten events ( $2 \%$ ) out of 420 calving events occurred underwater (Table 1). The location of subaqueous-calving events was unevenly distributed (Fig. 3). For example, we observed subaqueous-calving events only at distances $\sim 600,1000$ and $1200 \mathrm{~m}$ in period 1 where relatively larger number of subaerial calving was observed (Fig. $3 \mathrm{~d}$ ). It was suggested that as ice above the water level breaks off, overburden load counteraction to the buoyance decreases and
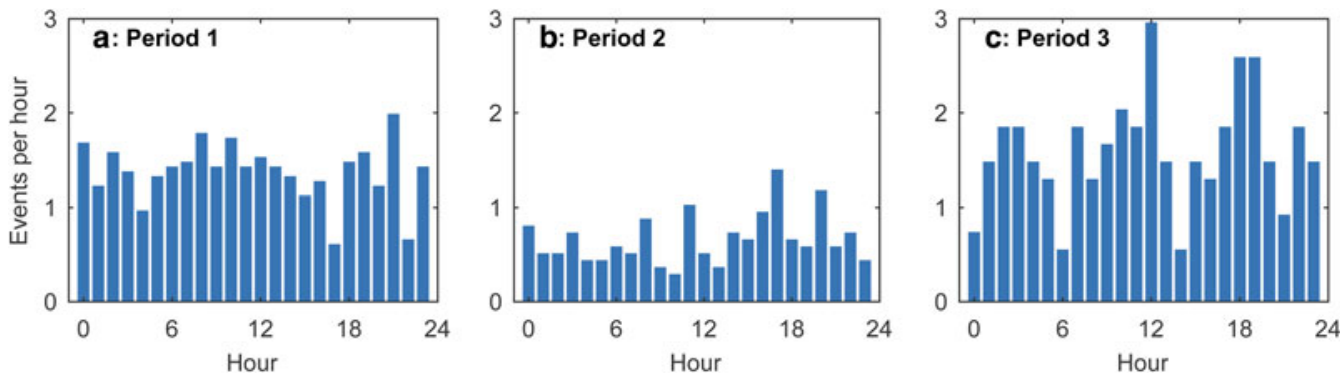

Fig. 7. Diurnal variations in the number of events detected from surface waves in (a) period 1, (b) period 2 and (c) period 3. 

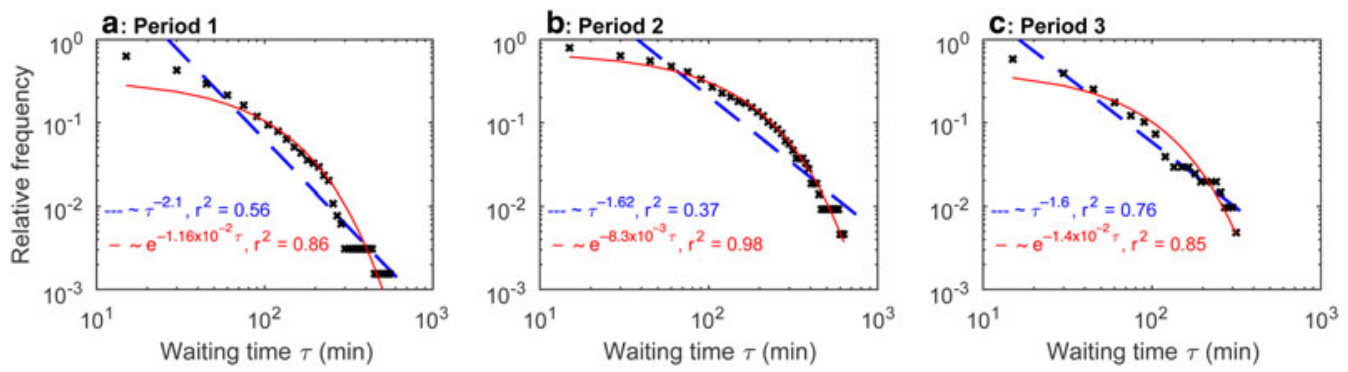

Fig. 8. Distributions of waiting times $\tau$ (with 15 min bins; log-log scale) in (a) period 1, (b) period 2 and (c) period 3. Blue dashed and solid red lines indicate best-fit power-law and exponential distribution.

subaqueous calving occurs (Van der Veen, 2002). Thus, a relatively large number of subaerial-calving events might trigger subaqueous calving at GPM. In addition to this, a number of subaqueous-calving events was substantially smaller than subaerial calving (Table 1). In GPM, a warm lakewater temperature $\left(\sim 9^{\circ} \mathrm{C}\right)$ was observed in front of the glacier compared with other proglacial lakes in Patagonia (Sugiyama and others, 2016). In fact, the latter study estimated that the magnitude of subaqueous-melt rate near the glacier front is $\sim 7-33 \%$ of the ice speed. The low frequency of subaqueous-calving events may imply that subaqueous melting rate is similar to subaerial-calving rate at GPM.

On the time-lapse images, a greater number of calving events were observed in periods 1 and 3 than in period 2 (Fig. 4). Some calving events were not recorded by the cameras due to a lack of sunlight and blind angles, but results from pressure sensor and time-lapse cameras agree that events were more frequent in periods 1 and 3 . The more frequent calving in periods 1 and 3 is associated with relatively warm air temperature. The mean air temperature over the periods measured near the glacier front was $8.5 \pm$ $2.4( \pm \mathrm{SD}), 3.1 \pm 1.9$ and $9.7 \pm 1.9^{\circ} \mathrm{C}$ for periods 1,2 and 3 , respectively. Minowa and others (2017) investigated seasonal variations in the ice front position of GPM based on satellite image analysis. The glacier began to retreat typically in December and then turned to advance in April (Minowa and others, 2017). The seasonal ice front variations $( \pm 100 \mathrm{~m})$ were controlled by frontal ablation, which varies from maximum in February to minimum in July. This seasonality is consistent with the number of calving events observed in this study (Fig. 4). The seasonal variation in the frontal ablation was correlated with lake and air temperatures, but not with the ice speed (Minowa and others, 2017), suggesting the importance of subaqueous melting and calving induced by waterline notch formation. Unlike the proglacial lakes in Alaska and New Zealand, where water temperature is cold $\left(<1^{\circ} \mathrm{C}\right)$ (e.g., Röhl, 2006; Truffer and Motyka, 2016), water is warm $\left(\sim 9^{\circ} \mathrm{C}\right)$ in front of GPM and temperature shows seasonal variations at all depths of the lake (Sugiyama and others, 2016; Minowa and others, 2017).
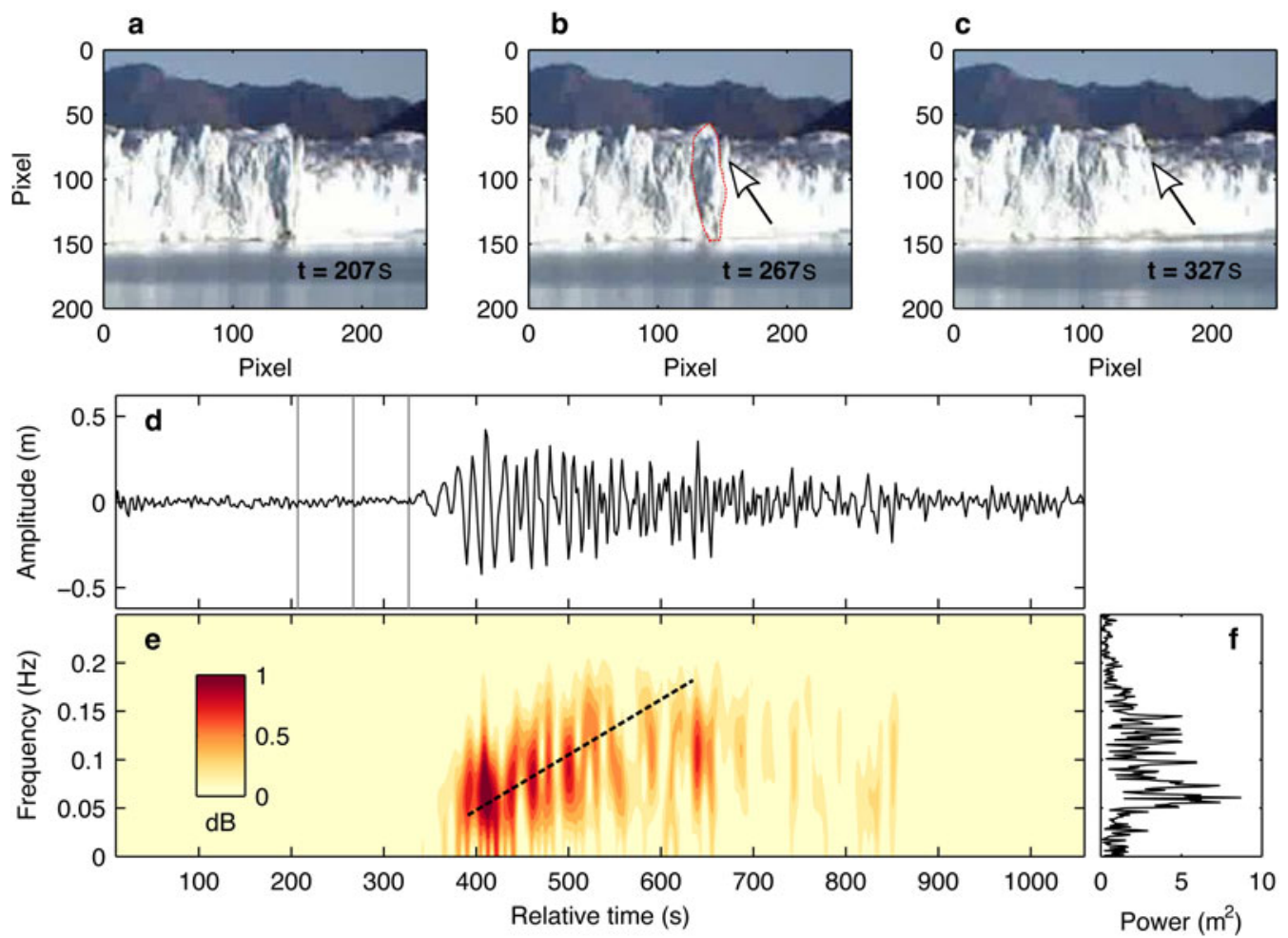

Fig. 9. (a)-(c) Time-lapse photograph sequence of a subaerial calving (Drop) which took place on 2 March 2016. The arrows indicate the main calving location and polygon shows an ice surface exposed after this event. (d) Surface waves generated by the calving, (e) spectrogram and (f) power spectrum. Gray vertical lines indicate the timing of images shown in (a)-(c). The dotted line highlights a relationship between the peak frequency and arrival time. 


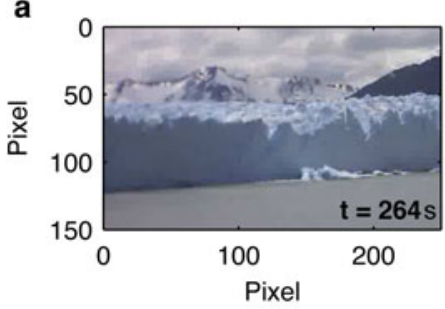

b

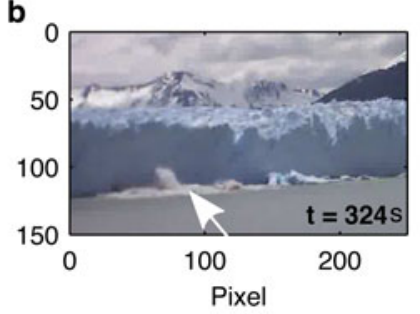

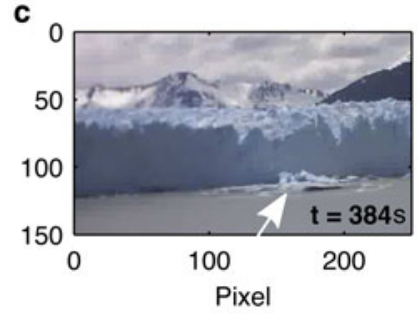

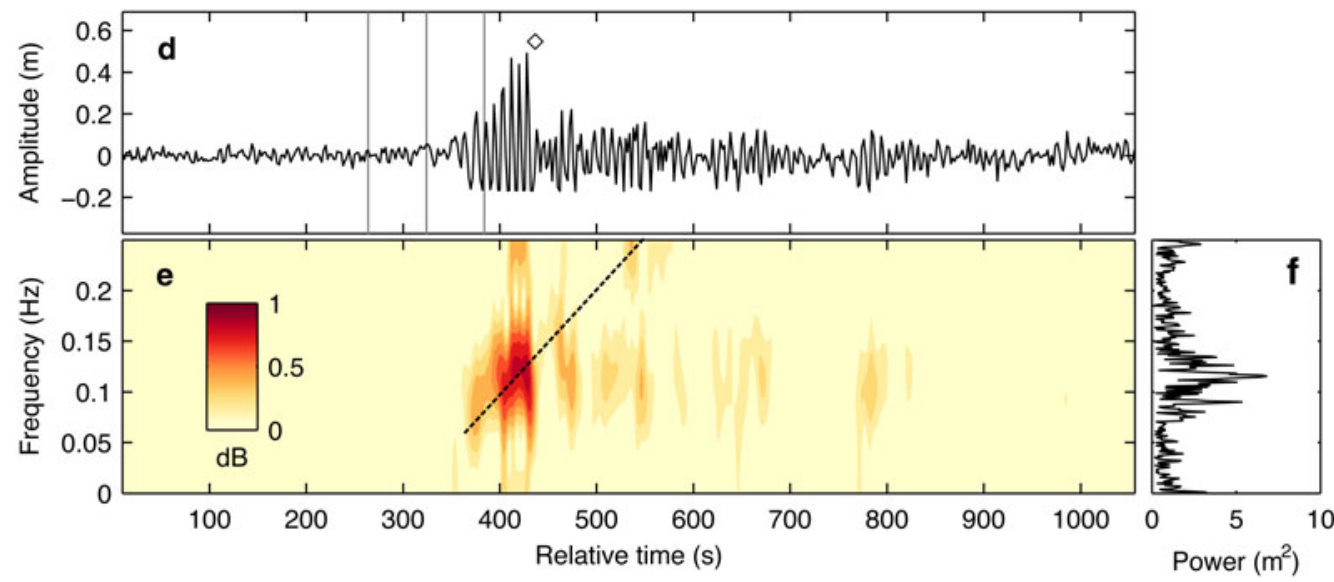

Fig. 10. (a)-(c) Time-lapse photograph sequence of subaqueous calving on 27 December 2013. (d) Surface waves generated by the calving (negative amplitude clipping was caused by a water-level drop below the sensor depth). The black diamond indicates the timing of sudden drop in the amplitude. (e) Spectrogram and ( $f$ ) power spectrum of the surface wave.

Thus, we attribute the higher calving frequency in periods 1 and 3 to the relatively warm lake-water conditions, which enhanced the melting of the ice front and induced more calving.

For additional statistical characterization, we also computed interevent time interval between calving events. The obtained cumulative distribution of interevent time intervals can be well represented by exponential probability distribution, especially for period 2 (Fig. 8b). Yet, in periods 1 and 3, power law modeled the distribution also reasonably well (Figs 8a, c). There are several previous studies reporting the probability distribution of calving waiting time. On one hand, Åström and others (2014) reported that modeled and observed waiting-time distributions tend to follow power laws, suggesting that calving behaves as a self-organized system readily fluctuating in response to changes in climate and geometric conditions. Although, one of their studied glaciers, Yahtse Glacier in Alaska, did not follow a power law but could be fitted well with an exponential distribution. On the other hand, Chapuis and Tetzlaff (2014); Petlicki and Kinnard (2016) reported that waiting-time distribution follows neither an exponential model nor a power law based on their observations at ocean-terminating glaciers in Svalbard and Antarctic Peninsula. Our results are in line with those observed at relatively small and grounded Yahtse Glacier in Alaska, implying that the events at GPM occur randomly in time.

\subsection{Source-to-receiver distance}

One possible application of surface waves data collection is the estimation of the source-to-sensor distances, which was previously applied in Antarctica, but not validated with data (MacAyeal and others, 2009). Source-to-sensor distance can be used to locate calving events, which would help to better understand driving mechanisms of calving. For deep- water waves, the arrival time of a surface wave can be assumed as linearly dependent on the wave frequency (MacAyeal and others, 2009). Therefore, Eqn (3) allows us to estimate the source-to-sensor distance from surface-wave observations alone (MacAyeal and others, 2009).

$$
\frac{\mathrm{d} f}{\mathrm{~d} t}=\frac{g}{4 \pi \Delta_{\mathrm{E}}}
$$

where $t$ is the arrival time of a wave with a frequency $f$. Equation (4) is used to determine distance $\Delta_{\mathrm{E}}$ from the measurements of $\mathrm{d} f / \mathrm{d} t$ that were obtained by fitting a linear relationship to the peak frequency in spectrograms (Figs 9, 10). First, we obtained peak frequency by calculating power spectral density repeatedly with the data window of 5-20 s with a $1 \mathrm{~s}$ time step (Figs $11 \mathrm{a}, \mathrm{b}$ ). Then, we performed linear regression, weighted by the power of the peak frequencies, to obtain $\mathrm{d} f / \mathrm{d} t$ and the SD. Weighted linear regression was performed again after excluding outliers deviated by more than one SD. Finally, we calculated its qualities of fitting $\left(r^{2}\right)$ as an index to evaluate $\Delta_{\mathrm{E}}$ (Fig. 11b). We analyzed 137 cases distributed over periods $1-3$ to compare the distance estimated using the above explained method and measured with the time-lapse and satellite imagery (Fig. 3). The mean $r^{2}$ of the entire sample of linear regression lines was 0.71 with an SD of 0.25 .

By visual inspection of Figure 11c, the reader will observe that the estimated source-to-sensor distance agrees well with the observation within $\sim 20 \%$. The RMSE of the estimated distance against the observation was $300 \mathrm{~m}$. The accuracy of the estimation is dependent on the wave magnitude at the peak frequency relative to the background noise. More reliable estimation is possible by increasing the number of pressure sensors. The deep-water condition assumed in the above calculation requires that the condition $h / L>0.5$ is satisfied, where the wavelength $L=g /(2 \pi) T^{2}$, with $t$ and $g$ standing 
a
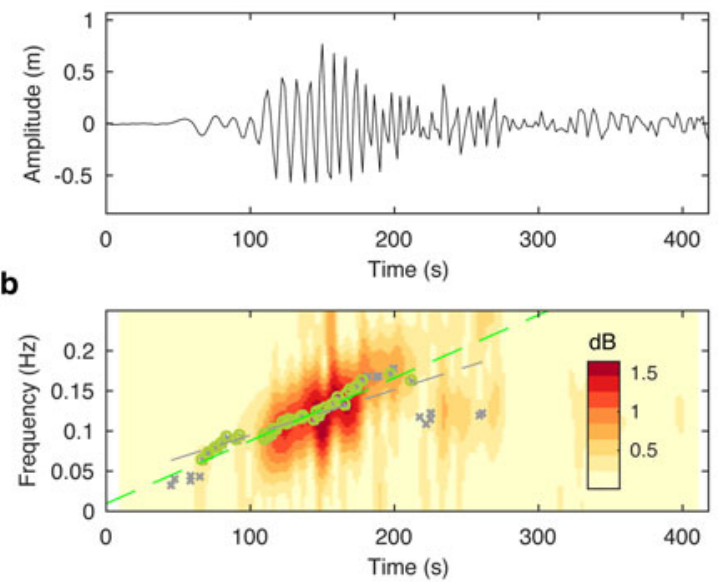

c

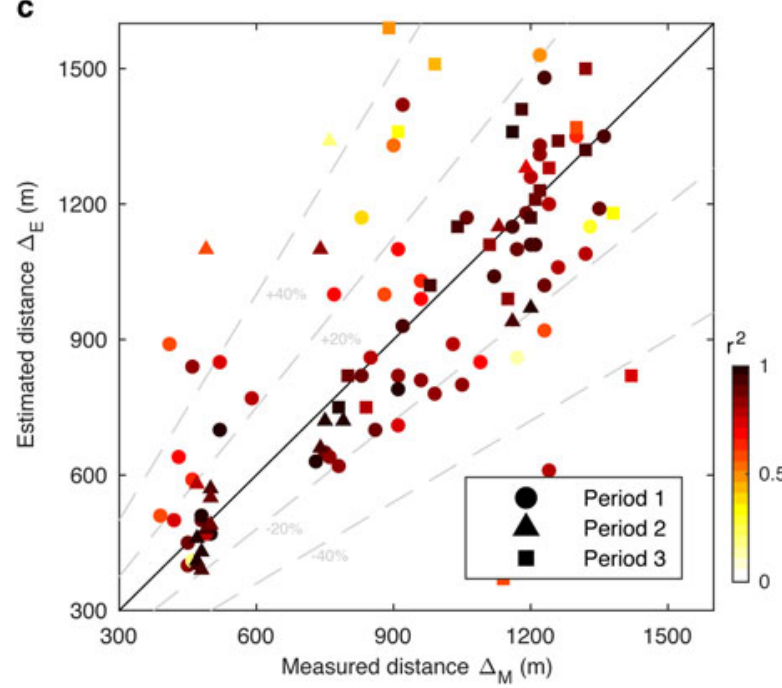

Fig. 11. (a) A waveform generated by a calving event (19 December $201311: 38-11: 44)$ as an example of the data used for the analysis. (b) Spectrogram of the wave shown in (a). Gray crosses and green circles are peak frequencies calculated with 5 and $20 \mathrm{~s}$ data windows, respectively. Gray and green dashed lines are weighted linear regression of the peak frequency. (c) Scatter plot of measured $\Delta_{\mathrm{M}}$ and estimated $\Delta_{\mathrm{E}}$ source-to-sensor distances. Marker color and type indicate coefficient of determination of the regression lines and observation period, respectively. The black line and gray dashed lines indicate 1:1 correspondence and relative error of estimated distance, respectively.

for wave period and gravitational acceleration, respectively. Considering the lake depth near the calving front (60-100 $\mathrm{m}$ ) and the dominant wave period of $9 \mathrm{~s}$, the study site places it almost at the threshold of the deep-water condition (8.8-11.3 s). Combining this important background with the fact that the dispersion was actually documented, we may assume that the accuracy of the source-to-receiver distance could be affected by travel path. However, sensitivity tests with high-pass-filtered waveforms (i.e., when we analyze only waves with periods shorter than the threshold) did not yield any obvious improvements. Finally, we note that if lakes and fjords in front of glaciers are too shallow, the method proposed here may not be applicable.

\subsection{Frequency characteristics of calving styles}

To understand the relationship between calving styles and properties of surface waves more clearly, as well as statistically, we performed spectral analysis of 420 surface waves, for which calving styles were categorized based on time-lapse images. Obtained power spectra were averaged for each calving style and normalized by the maximum power before the comparison. Our data demonstrate that subaerial- and subaqueous-calving events generate waves with different characteristics, suggesting either that (i) waveforms and frequencies of waves are dependent on the calving style, or (ii) the difference is due to path effects (Fig. 12).

All of the calving-generated surface waves show a peak frequency $\sim 0.11 \mathrm{~Hz}$ (Fig. 12a). While the number of subaqueous-calving events was limited compared with subaerial-calving events, waves generated by subaqueous calving were characterized by a lack of high-frequency waves between 0.12 and $0.25 \mathrm{~Hz}$, and the peak frequency power was more pronounced compared with subaerial calving (Fig. 12a). This difference could be explained by scales associated to iceberg detachment from the glacier front. If subaerial calving produces smaller icebergs and splashes of different sizes, the associated impacts are supposed to generate higher frequency waves. According to our time-lapse images, subaqueous calving is characterized by a single, relatively large iceberg floating up to the lake surface. Thus, spectral differences could be related to a difference of scales, which, however, is difficult to verify by visual inspection of time-lapse photographs due to largely unseen volume of subaqueous icebergs.

Slightly different frequency distributions were observed among the three subaerial-calving styles: Serac, Drop and
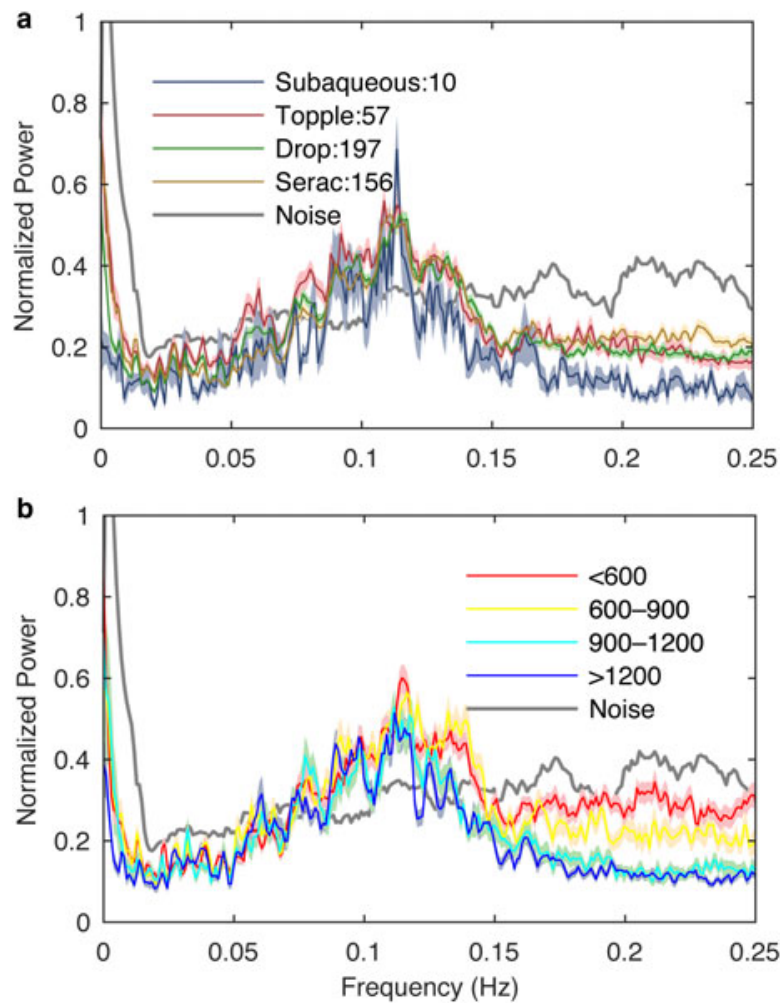

Fig. 12. (a) Power spectra of the waves generated by the four different calving styles. Each solid curve obtained by taking the mean of all events categorized as each style with a sample number indicated in the legend. The shade indicates standard error distribution of the data. Gray line indicates power spectra of background noise for 100 min wave record. (b) Power spectra of the waves generated by the Drop calving styles with different distances from the pressure sensor. 
Topple (Fig. 12a). In general, surface waves after Topple and Serac style events had greater power in the lower (e.g., $\sim 0.06 \mathrm{~Hz}$ ) and higher frequency bands (e.g., $\sim 0.23 \mathrm{~Hz}$ ), respectively. These results are consistent with a modeling study of Massel and Przyborska (2013), which suggested that longer and shorter period waves characterize those generated by Topple and Serac events.

The presented frequency difference was observed repeatedly and visible in averaged spectra for ten-to-hundreds events (Fig. 12a). However, the spectral differences between calving styles could be simply generated by path effects, in particular by faster attenuation of high-frequency waves with distance. To asses this possibility, we calculated normalized power spectra of several Drop-type calving events taking place at different distances (Fig. 12b). Such analysis suggested: (i) first, that the dominant period remained the same at different distances, confirming that the peak frequency of tsunami signals were not significantly affected by the distance; (ii) second, that at distances larger than $1 \mathrm{~km}$, high-frequency energy between 0.12 and $0.25 \mathrm{~Hz}$ can be reduced (Fig. 12b). Closer events had 10-20\% higher power at the higher frequencies. This indicates that highfrequency waves may attenuate more with distance while low-frequency waves do not. Considering a lack of subaquaous-calving events at shorter distances, and an abundance of subaerial events at close distances (Fig. 3), path effects can be responsible for spectral differences shown in Figure 12a. The above-mentioned analysis implies that even if spectral differences between subaerial- and subaquaous-calving exist, it can be difficult or impossible to classify distant events.

Finally, it is interesting to asses a possibility of distorting interference of local bathymetry and path effects on the dominant period of the presented tsunami spectra. It is well known from research on tsunami source reconstruction, that near-shore tsunami records can be determined mainly by local topography effects. According to Rabinovich (1997), the key approach to separate such influence is based on comparative analysis of tsunami and background noise spectra. Many observations show that background and tsunami spectra were generally in good agreement, meaning that the tsunami record is influenced by the natural resonance of the tide gauge neighboring topography. We check if such distorting influence appears in our records by computing the spectra of noise (for a quiet time interval of 100 min without calving events) and comparing it with the spectra of calving events (Fig. 12). This analysis shows that noise is relatively broadband and does not have obvious peaks which could correspond to seiches or maximum amplitudes produced by micro-tsunamis, and therefore, suggests that a possibility of local interference of local bathymetry is insignificant.

\subsection{Iceberg size and wave properties}

One of the practical applications of surface-wave measurements is the estimation of iceberg volume released by calving events. Recent studies endeavor to estimate calving flux by using seismic and acoustic signals (Bartholomaus and others, 2015; Glowacki and others, 2015). In order to explore the relationship between iceberg volume and wave properties, we estimated the volume from the time-lapse images and compared it with median frequency and maximum height of the wave. Geometric attenuation in the surface-wave amplitude (e.g., Podolskiy and Walter, 2016) was taken into account by multiplying the wave height with $\sqrt{\Delta_{M}}$, where $\Delta_{M}$ is the measured distance to the source. In total, 92 events observed over the three periods were considered for this analysis (Fig. 13a). Ice surface area $\left(A_{C}\right)$ exposed after the calving was manually quantified by comparing images taken before and after the subaerialcalving events (e.g., Fig. 9 red line). We converted the unit of $A_{C}$ from image scale pixel to real world scale $m$ by using a relationship $f_{\mathrm{I}}^{2} / A_{\mathrm{C}_{-} \text {img }}=d^{2} / A_{\mathrm{C}_{\text {_real }}}$, where $f_{\mathrm{I}}$ and $d$ are the focal length of the camera $(5.01 \mathrm{~mm})$ and a distance between the cameras and calving locations, respectively. Sensor size of the time-lapse camera was $6.4 \times 5.1 \mathrm{~mm}$ $(1 \mathrm{px}=5 \mu \mathrm{m})$. $d$ was derived from manual comparison between Landsat imagery and the time-lapse photographs using easily discernible features. We used only images taken by cameras 2, 3 and 4, which were oriented more perpendicular to the ice front (Figs $3 \mathrm{~h}-\mathrm{j}$ ). Iceberg volume was then calculated by $V_{C}=C A_{C}^{3 / 2}$, by assuming that the depth of the calved ice is proportional to the square root of newly exposed area. $C$ is a constant scaling factor that is found to be 0.12 (Åström and others, 2014; Petlicki and Kinnard, 2016). The assumption is supported by previous observations of ocean-terminating glaciers in Svalbard (Dowdeswell and Forsberg, 1992) and was successfully applied for studying a ocean-terminating glacier in Antarctica (Petlicki and Kinnard, 2016). The accuracy of $V_{C}$ is difficult to estimate because the exposed ice surface is not perfectly perpendicular to the sight of the camera and the iceberg shapes are
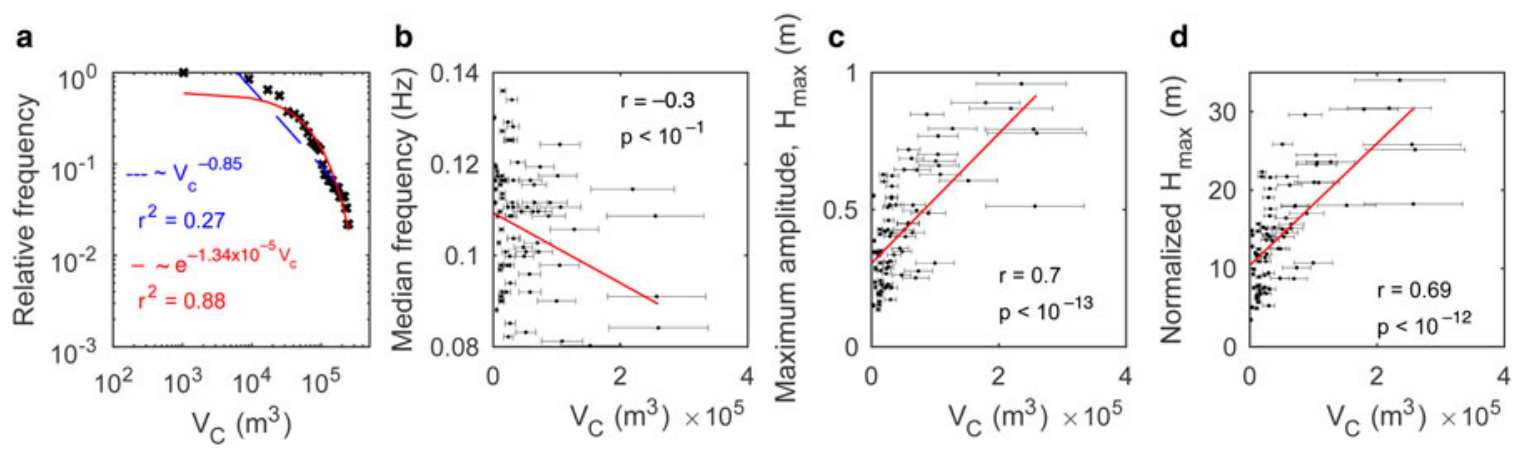

Fig. 13. (a) Distribution of iceberg size $V_{\mathrm{C}}$ (with $8 \times 10^{3} \mathrm{~m}^{3}$ bins; log-log scale). Blue dashed and red solid lines indicate best-fit power-low and exponential distribution. Scatter plots for iceberg size versus (b) median frequency, (c) maximum amplitude and (d) maximum amplitude corrected for source-to-sensor distance $\Delta_{M}$ (i.e., $\left.H_{\max } \times \sqrt{\Delta_{M}}\right)$. 
irregular. If we assume $10 \%$ of error bound in $A_{C_{-} \text {img }}$ and $d$, and each of these uncertainties are independent, an error associated with the image analysis is $30 \%$.

Figure 13a shows a cumulative distribution function of iceberg volume $V_{\mathrm{C}}$. The observed distribution was modeled by best-fit power-law and exponential models. The iceberg volume ranged from the minimum of $1.04 \times 10^{3} \mathrm{~m}^{3}$ to the maximum of $2.6 \times 10^{5} \mathrm{~m}^{3}$, with a mean $V_{\mathrm{C}}$ equal to $4.9 \times$ $10^{4} \mathrm{~m}^{3}$. These numbers were consistent with the previous studies on relatively small, grounded ocean-terminating glaciers in Alaska, Svalbard and Antarctica (Bartholomaus and others, 2012; Chapuis and Tetzlaff, 2014; Petlicki and Kinnard, 2016). However, compared with these previous studies, the distribution of iceberg volume could be better reproduced by an exponential model than by the power law (Fig. 13a). Among possible reasons for this disagreement are: a small sample size $(n=92)$ or some real physical difference between calving at ocean-terminating and lake-terminating glaciers (e.g., Benn and others, 2007), which remains to be clarified by future studies.

A relationship was observed between the iceberg size and the maximum amplitude of the surface waves (Fig. 13). Median frequency showed slightly negative relationship, and maximum wave amplitudes and their normalized values showed positive relationships with the iceberg size. Intuitively, one can expect that there may be a negative relationship between frequency and iceberg size; i.e., it is reasonable to speculate that small iceberg calving (Serac) tend to have their peak frequency at a higher frequency, while larger calving styles (Topple and Drop types) tend to have it at the lower frequency. Nevertheless, there is inconclusive evidence about the significance of the correlation between the median frequency and the iceberg volume (Fig. 13b). This could suggest that: (i) the distribution of iceberg sizes was too limited due to the site conditions to observe a wide variation of the dominant frequency; or alternatively, (ii) be caused by path effects (i.e., effects from lake topography). Contrary to the median frequency, we observed a clearer relationship between maximum amplitude and size (Figs 13c, d). Since maximum amplitude decays with distance, we expected a positive relationship would become clearer if we compare normalized maximum amplitude with iceberg size. However, the effect of normalization was limited. There are some data which do not fit the linear regression (Figs 13c, d). To investigate how sensitive this relationship is to outliers, we excluded those deviated by more than one SD and performed linear regression again. The linear regression model changed only 5.2 and $5.4 \%$ from the original regression models. Thus, the effect of the outliers was limited. These results indicate that maximum wave amplitude has a potential to be used as a proxy for the calving flux. However, to find a quantitative relationship between the calving flux and surface waves, we need to quantify iceberg size more precisely by analyzing high-resolution digital elevation models.

\subsection{Comparison with Antarctic micro-tsunami}

MacAyeal and others (2009) recognized that seismic observations of glaciogenic ocean waves (micro-tsunamis) are useful for studying calving and other processes of ice shelves in Antarctica. Over a 3-year observation, seismometer arrays on the Ross Ice Shelf and several icebergs recorded 368 impulsive events with a duration between 1 and $30 \mathrm{~min}$ and dominant frequencies of $0.05-0.2 \mathrm{~Hz}$. These local ocean-wave signals were attributed to a wide range of glaciological sources, such as small-scale calving, iceberg capsizing and collision, rift propagation, tidal ice motion in the grounding zone and submarine landslides. Surface waves observed in front of GPM had similar duration and spectral properties to those documented by MacAyeal and others (2009). Iceberg calving was suggested as the most likely source of wave-arrival events in the coastal Antarctic waters (MacAyeal and others, 2009). Our groundvalidated analysis (and clear association of surface-wave signals with calving) confirms their hypothesis.

Furthermore, MacAyeal and others (2009) computed source-to-receiver distances for the events in their catalog by using the dispersion relationship at deep-water limit. The obtained values corresponded to distances from $\sim 10$ to $700 \mathrm{~km}$. Similar method employed in our study yielded two-orders-of-magnitude shorter distances, which agreed reasonably well with the results of time-lapse imagery.

Finally, we note that in the ocean, background noise can increase due to trans-oceanic sea swell, which makes detection of glaciogenic waves in the sub- $0.15 \mathrm{~Hz}$ range impossible (MacAyeal and others, 2009). From this perspective, a lack of time periods with such noise makes the discussed methodology more useful at lake-terminating glaciers. In general, we conclude that the pioneering idea to focus on micro-tsunami signals (MacAyeal and others, 2009) will continue to be useful in the study of iceberg-calving.

\section{CONCLUSIONS}

We observed surface waves generated by calving events using a pressure sensor installed in front of a lake-terminating glacier in Patagonia. The surface-wave measurements were accompanied by time-lapse photography to record the locations and styles of calving. During three field campaigns over $39 \mathrm{~d}$ in total, we counted on photographs 420 calving events, which were dominated by subaerial-calving style (98\%). The events were non-uniformly distributed along the ice front because calving occurred more frequently at the region characterized by shallow bathymetry and large gaps between crevasses. Comparison of time-lapse images and surface-water wave measurements shows that iceberg calving generates waves that are distinct from local noise, such as tourist boats and wind. This allowed us to count 1074 calving events from surface-wave records, including those that were not observable by the camera. The data indicate that calving events took place $\sim 2.6$ times more frequently in December and March (austral summer) than in October (austral spring), while calving front position remained relatively stable between the considered periods. The distributions of calving-interevent time and iceberg size appear to be exponential, but it remains to be understood if this can be called a prominent feature of lake-terminating glaciers or not.

Interestingly, waves generated by subaerial and subaqueous calving showed similar frequency dispersion, which is common only for the so-called deep water. To assess the potential to use surface waves for glacier-calving monitoring, we estimated source-to-sensor distance by assuming a linear relationship between wave frequencies and their arrival time at the sensor. The results agreed with the distance measured by the time-lapse images within $\sim 20 \%$ errors. Our analysis also suggested that waves generated by subaqueous 
calving are characterized by a lack of power between 0.12 and $0.25 \mathrm{~Hz}$. However, considering that most of the observed subaquaous events were relatively far from the receiver, attenuation of high-frequency energy could be responsible for such feature, meaning that it remains to be clarified by future research if power spectrum of surface waves really depends on the style of calving. Finally, we found relationships between calving volume estimated from time-lapse images and maximum amplitude. Therefore, our study demonstrated a potential to monitor the occurrence, location and volume of calving events with a relatively simple surface-wave measurement.

Long-term monitoring of calving by means of surfacewave measurements should help to better constrain the driving mechanisms of calving at GPM and other glaciers. Due to the complexity of effects from local bathymetry and wave paths (both at the source and receiver locations) on waveforms, further investigations are needed to improve the results explored in this paper. For instance, an open question about an existence of a robust relationship between iceberg volume or type and waveforms could be addressed with accurate measurements of iceberg volume and modeling in future studies.

\section{CONTRIBUTION STATEMENT}

M.M. analyzed data, made the figures and wrote the paper. E. P. contributed to the analysis of waveforms and dispersion and wrote the paper. S.S. designed the field activities at the glacier and contributed to writing the paper. M.M., S.S., D.S. and P.S. contributed to the fieldwork. All authors contributed to the discussion of the results and participated in the writing of the paper.

\section{ACKNOWLEDGEMENTS}

We thank Y. Ohashi, T. Sawagaki and N. Naito for their help in the field. Special thanks to Hielo y Aventura for logistical support. The manuscript was improved by comments and suggestions from M. Truffer, and handled by Scientific Editor, Hamish Pritchard, and carefully commended by Martin Lüthi and an anonymous reviewer. This research was supported by the Japan Society for the Promotion of Science; Grants-in-Aid for Scientific Research JP23403006, JP26550001 and JP16H05734; Grant-in-Aid for JSPS Research Fellow JP16J01860; and by the Inoue Found for Field Science of the Japanese Society of Snow and Ice. Landsat images were downloaded from http://earthexplorer. usgs.gov/.

\section{REFERENCES}

Amundson JM and 5 others (2008) Glacier, fjord, and seismic response to recent large calving events, Jakobshavn Isbræ, Greenland. Geophys. Res. Lett., 35(22) (doi: 10.1029/ 2008GL035281)

Amundson JM and 5 others (2010) Ice mélange dynamics and implications for terminus stability, Jakobshavn Isbræ, Greenland. J. Geophys. Res. Earth, 115(F1) (doi: 10.1029/2009JF001405)

Aniya M, Sato H, Naruse R, Skvarca P and Casassa G (1997) Recent glacier variations in the Southern Patagonia icefield, South America. Arct. Alp. Res., 29(1), 1-12 (doi: 10.2307/1551831)

Arendt AA, Echelmeyer KA, Harrison WD, Lingle CS and Valentine VB (2002) Rapid wastage of Alaska glaciers and their contribution to rising sea level. Science, 297(5580), 382-386 (doi: 10.1126/science.1072497)

Åström JA and 10 others (2014) Termini of calving glaciers as selforganized critical systems. Nat. Geosci., 7, 874-878 (doi: 10.1038/ngeo2290)

Bartholomaus T, Larsen C, O'Neel S and West M (2012) Calving seismicity from iceberg-sea surface interactions. J. Geophys. Res. Earth, 117(F4) (doi: 10.1029/2012JF002513)

Bartholomaus T and 5 others (2015) Tidal and seasonal variations in calving flux observed with passive seismology. J. Geophys. Res. Earth, 120(11), 2318-2337 (doi: 10.1002/2015JF003641)

Bassis J and Jacobs S (2013) Diverse calving patterns linked to glacier geometry. Nat. Geosci., 6(10), 833-836 (doi: 10.1038/ngeo1887)

Bassis JN, Fricker HA, Coleman R and Minster JB (2008) An investigation into the forces that drive ice-shelf rift propagation on the Amery Ice Shelf, East Antarctica. J. Glaciol., 54(184), 17-27 (doi: 10.3189/002214308784409116)

Benn DI, Warren CR and Mottram RH (2007) Calving processes and the dynamics of calving glaciers. Earth Sci. Rev., 82(3), 143-179 (doi: 10.1016/j.earscirev.2007.02.002)

Boyce ES, Motyka RJ and Truffer M (2007) Flotation and retreat of a lake-calving terminus, Mendenhall Glacier, southeast Alaska, USA. J. Glaciol., 53(181), 211-224 (doi: 10.3189/ 172756507782202928)

Bromirski PD and Duennebier FK (2002) The near-coastal microseism spectrum: spatial and temporal wave climate relationships. J. Geophys. Res. Solid Earth, 107(B8), ESE5-1-ESE 5-20 (doi: 10.1029/2001JB000265)

Chapuis A and Tetzlaff T (2014) The variability of tidewater-glacier calving: origin of event-size and interval distributions. J. Glaciol., 60(222), 622-634 (doi: 10.3189/2014JoG13J215)

Chen X, Shearer P, Walter F and Fricker H (2011) Seventeen Antarctic seismic events detected by global surface waves and a possible link to calving events from satellite images. J. Geophys. Res. Solid Earth, 116(B6) (doi: 10.1029/2011) B008262)

De Angelis H (2014) Hypsometry and sensitivity of the mass balance to changes in equilibrium-line altitude: the case of the Southern Patagonia Icefield. J. Glaciol., 60(219), 14-28 (doi: 10.3189/ 2014JoG13J127)

Deane GB, Glowacki O, Tegowski J, Moskalik $\mathrm{M}$ and Blondel P (2014) Directionality of the ambient noise field in an Arctic, glacial bay. J. Acoust. Soc. Am., 136(5), EL350-EL356 (doi: 10.1121/1.4897354)

Dowdeswell JA and Forsberg CF (1992) The size and frequency of icebergs and bergy bits derived from tidewater glaciers in Kongsfjorden, northwest Spitsbergen. Polar Res., 11(2), 81-91 (doi: 10.1111/j.1751-8369.1992.tb00414.x)

Enderlin EM and 5 others (2014) An improved mass budget for the Greenland ice sheet. Geophys. Res. Lett., 41(3), 866-872 (doi: 10.1002/2013GL059010)

Gardner AS and 9 others (2013) A reconciled estimate of glacier contributions to sea level rise: 2003 to 2009. Science, 340 (6134), 852-857 (doi: 10.1126/science.1234532)

Glowacki $O$ and 5 others (2015) Underwater acoustic signatures of glacier calving. Geophys. Res. Lett., 42(3), 804-812 (doi: 10.1002/2014GL062859)

Hanson B and Hooke RL (2003) Buckling rate and overhang development at a calving face. J. Glaciol., 49(167), 577-586 (doi: 10.3189/172756503781830476)

Haresign EC (2004) Glacio-limnological interactions at lake-calving glaciers. Ph.D. thesis, University of St Andrews

Horikawa K and Kuo CT (1966) A study on wave transformation inside surf zone. Coast. Eng. Proc., 1(10) (doi: 10.9753/icce. v10.\%p)

Howat IM, Joughin I and Scambos TA (2007) Rapid changes in ice discharge from Greenland outlet glaciers. Science, 315(5818), 1559-1561 (doi: 10.1126/science.1138478)

Hunter LE and Powell RD (1998) Ice foot development at temperate tidewater margins in Alaska. Geophys. Res. Lett., 25(11), 19231926 (doi: 10.1029/98GL01403) 
lizuka Y, Kobayashi S and Naruse R (2004) Water surface waves induced by calving events at Perito Moreno Glacier, southern Patagonia. Bull. Glaciol. Res., 21, 91-96

Jacob T, Wahr J, Pfeffer WT and Swenson S (2012) Recent contributions of glaciers and ice caps to sea level rise. Nature, 482(7386), 514-518 (doi: 10.1038/nature10847)

James TD, Murray T, Selmes N, Scharrer K and O'Leary M (2014) Buoyant flexure and basal crevassing in dynamic mass loss at Helheim Glacier. Nat. Geosci., 7(8), 593-596 (doi: 10.1038/ ngeo2204)

Kirkbride MP and Warren CR (1997) Calving processes at a grounded ice cliff. Ann. Glaciol., 24, 116-121

Köhler A, Chapuis A, Nuth C, Kohler J and Weidle C (2012) Autonomous detection of calving-related seismicity at Kronebreen, Svalbard. Cryosphere, 6(2), 393-406 (doi: 10.5194/tc-6-393-2012)

Köhler A, Nuth C, Schweitzer J, Weidle C and Gibbons SJ (2015) Regional passive seismic monitoring reveals dynamic glacier activity on Spitsbergen, Svalbard. Polar Res., 34 (doi: 10.3402/ polar.v34.26178)

Köhler A and 5 others (2016) A 15 year record of frontal glacier ablation rates estimated from seismic data. Geophys. Res. Lett., 43 (23), 12,155-12,164 (doi: 10.1002/2016GL070589)

Lamb H (1932) Hydrodynamics. Cambridge University Press, Cambridge.

Larsen C and 5 others (2015) Surface melt dominates Alaska glacier mass balance. Geophys. Res. Lett., 42(14), 5902-5908 (doi: 10.1002/2015GL064349)

Lazzara M, Jezek K, Scambos T, MacAyeal D and Van der Veen C (1999) On the recent calving of icebergs from the Ross Ice Shelf. Polar Geogr., 23(3), 201-212 (doi: 10.1080/ 10889379909377676)

Lenaerts JT and 6 others (2014) Extreme precipitation and climate gradients in Patagonia revealed by high-resolution regional atmospheric climate modeling. J. Clim., 27(12), 4607-4621 (doi: 10.1175/JCLI-D-13-00579.1)

Lopez $\mathrm{P}$ and 5 others (2010) A regional view of fluctuations in glacier length in Southern South America. Glob. Planet. Change, 71(1), 85-108 (doi: 10.1016/j.gloplacha.2009.12.009)

Lüthi MP and Vieli A (2016) Multi-method observation and analysis of a tsunami caused by glacier calving. Cryosphere, 10(3), 9951002 (doi: 10.5194/tc-10-995-2016)

MacAyeal DR and 9 others and others (2006) Transoceanic wave propagation links iceberg calving margins of Antarctica with storms in tropics and Northern Hemisphere. Geophys. Res. Lett., 33(17), L17502 (doi: 10.1029/2006GL027235)

MacAyeal DR, Okal EA, Aster RC and Bassis JN (2009) Seismic observations of glaciogenic ocean waves (micro-tsunamis) on icebergs and ice shelves. J. Glaciol., 55(190), 193-206 (doi: 10.3189/002214309788608679)

Marchenko A, Morozov E and Muzylev S (2012) A tsunami wave recorded near a glacier front. Nat. Hazard. Earth Syst., 12(2), 415-419 (doi: 10.5194/nhess-12-415-2012)

Massel SR and Przyborska A (2013) Surface wave generation due to glacier calving. Oceanologia, 55(1), 101-127 (doi: 10.5697/ oc.55-1.101)

Meier M and Post A (1987) Fast tidewater glaciers. J. Geophys. Res. Solid Earth, 92(B9), 9051-9058 (doi: 10.1029/JB092 iB09p09051)

Minowa M, Sugiyama S, Sakakibara D and Skvarca P (2017) Seasonal variations in ice-front position controlled by frontal ablation at Glaciar Perito Moreno, the Southern Patagonia Icefield. Front. Earth Sci., 5, 1 (doi: 10.3389/feart.2017.00001)

Motyka RJ, Hunter L, Echelmeyer KA and Connor C (2003) Submarine melting at the terminus of a temperate tidewater glacier, LeConte Glacier, Alaska, USA. Ann. Glaciol., 36(1), 57-65 (doi: 10.3189/172756403781816374)

Munk WH, Miller G, Snodgrass F and Barber N (1963) Directional recording of swell from distant storms. Philos. Trans. R. Soc. A, 255(1062), 505-584
Naruse R, Fukami H and Aniya M (1992) Short-term variations in flow velocity of Glaciar Soler, Patagonia, Chile. J. Glaciol., 38 (128), 152-156

Nettles M and Ekström G (2010) Glacial earthquakes in Greenland and Antarctica. Annu. Rev. Earth Planet. Sci., 38(1), 467 (doi: 10.1146/annurev-earth-040809-152414)

O'Neel S, Marshall H, McNamara D and Pfeffer W (2007) Seismic detection and analysis of icequakes at Columbia Glacier, Alaska. J. Geophys. Res. Earth, 112(F3) (doi: 10.1029/2006 JF000595)

Petlicki M and Kinnard C (2016) Calving of Fuerza Aérea Glacier (Greenwich Island, Antarctica) observed with terrestrial laser scanning and continuous video monitoring. J. Glaciol., 62(235), 835-846 (doi: 10.1017/jog.2016.72)

Pettit EC (2012) Passive underwater acoustic evolution of a calving event. Ann. Glaciol., 53(60), 113-122 (doi: 10.3189/2012 AoG60A137)

Pettit EC, Nystuen JA and O'Neel S (2012) Listening to glaciers: passive hydroacoustics near marine-terminating glaciers. Oceanography, 25(3), 104-105 (doi: 10.5670/oceanog. 2012.81)

Pettit EC and 5 others (2015) Unusually loud ambient noise in tidewater glacier fjords: a signal of ice melt. Geophys. Res. Lett., 42 (7), 2309-2316 (doi: 10.1002/2014GL062950)

Podolskiy EA and Walter F (2016) Cryoseismology. Rev. Geophys., 54(4), 708-758, ISSN 1944-9208 (doi: 10.1002/2016 RG000526), 2016RG000526

Rabinovich AB (1997) Spectral analysis of tsunami waves: separation of source and topography effects. J. Geophys. Res. Oceans, 102(C6), 12663-12676 (doi: 10.1029/97JC00479)

Rignot E, Rivera A and Casassa G (2003) Contribution of the Patagonia Icefields of South America to sea level rise. Science, 302(5644), 434-437 (doi: 10.1126/science.1087393)

Rignot E, Jacobs S, Mouginot J and Scheuchl B (2013) Ice-shelf melting around Antarctica. Science, 341(6143), 266-270 (doi: 10.1126/science.1235798)

Röhl K (2006) Thermo-erosional notch development at fresh-watercalving Tasman Glacier, New Zealand. J. Glaciol., 52(177), 203213 (doi: 10.3189/172756506781828773)

Sakakibara D and Sugiyama S (2014) Ice-front variations and speed changes of calving glaciers in the Southern Patagonia Icefield from 1984 to 2011. J. Geophys. Res. Earth, 119(11), 25412554 (doi: 10.1002/2014JF003148)

Schaefer M, Machguth H, Falvey M, Casassa $G$ and Rignot $E$ (2015) Quantifying mass balance processes on the Southern Patagonia Icefield. Cryosphere, 9(1), 25-35 (doi: 10.5194/tc-925-2015)

Shipton E (1963) Land of tempest: travels in Patagonia, 1958-62. Hodder and Stoughton, London.

Stuefer M (1999) Investigations on mass balance and dynamics of Moreno Glacier based on field measurements and satellite imagery. Unpublished PhD dissertation, Universität Innsbruck

Sugiyama S and 7 others (2016) Thermal structure of proglacial lakes in Patagonia. J. Geophys. Res. Earth, 121, 2270-2286 (doi: 10.1002/2016JF004084)

Truffer M and Motyka RJ (2016) Where glaciers meet water: subaqueous melt and its relevance to glaciers in various settings. Rev. Geophys., 54(1), 220-239 (doi: 10.1002/2015RG000494)

Trüssel BL, Motyka RJ, Truffer M and Larsen CF (2013) Rapid thinning of lake-calving Yakutat Glacier and the collapse of the Yakutat Icefield, southeast Alaska, USA. J. Glaciol., 59(213), 149-161 (doi: 10.3189/2013J0G12J081)

Tsai VC, Rice JR and Fahnestock M (2008) Possible mechanisms for glacial earthquakes. J. Geophys. Res. Earth, 113(F3) (doi: 10.1029/2007JF000944)

van den Broeke $M$ and 8 others (2009) Partitioning recent Greenland mass loss. Science, 326(5955), 984-986 (doi: 10.1126/science. 1178176)

Van der Veen C (2002) Calving glaciers. Prog. Phys. Geogr., 26(1), 96-122 (doi: 10.1191/0309133302pp327ra) 
Vaňková I and Holland DM (2016) Calving signature in ocean waves at Helheim Glacier and Sermilik Fjord, East Greenland. J. Phys. Oceanogr., 46(10) (doi: 10.1175/JPO-D-15-0236.1)

Walter F, Olivieri M and Clinton JF (2013) Calving event detection by observation of seiche effects on the Greenland fjords. J. Glaciol., 59(213), 162-178 (doi: 10.3189/2013JoG12J118)

Warren C and Aniya M (1999) The calving glaciers of Southern South America. Glob. Planet. Change, 22(1), 59-77 (doi: 10.1016/S0921-8181(99)00026-0)
Warren C, Benn D, Winchester V and Harrison S (2001) Buoyancydriven lacustrine calving, Glaciar Nef, Chilean Patagonia. J. Glaciol., 47(156), 135-146 (doi: 10.3189/17275650 1781832403)

Willis MJ, Melkonian AK, Pritchard ME and Rivera A (2012) Ice loss from the Southern Patagonian Ice Field, South America, between 2000 and 2012. Geophys. Res. Lett., 39(17) (doi: 10.1029/ 2012GL053136)

MS received 28 August 2017 and accepted in revised form 6 March 2018; first published online 12 April 2018 